\title{
When Nudges Fail: Slippery Defaults
}

\section{Citation}

Lauren E. Willis, When Nudges Fail: Slippery Defaults, 80 U. Chi. L. Rev. 1157 (2013).

\section{Permanent link}

http://nrs.harvard.edu/urn-3:HUL.InstRepos:11215415

\section{Terms of Use}

This article was downloaded from Harvard University's DASH repository, and is made available under the terms and conditions applicable to Open Access Policy Articles, as set forth at http:// nrs.harvard.edu/urn-3:HUL.InstRepos:dash.current.terms-of-use\#OAP

\section{Share Your Story}

The Harvard community has made this article openly available.

Please share how this access benefits you. Submit a story.

Accessibility 


\title{
When Nudges Fail: Slippery Defaults
}

\author{
Lauren E. Willis†
}

Inspired by the success of "automatic enrollment" in increasing participation in defined contribution retirement savings plans, policymakers have put similar policy defaults in place in a variety of other contexts, from checking account overdraft coverage to home-mortgage escrows. Internet privacy appears poised to be the next arena. But how broadly applicable are the results obtained in the retirementsavings context? Evidence from other contexts indicates two problems with this approach: the defaults put in place by the law are not always sticky, and the people who opt out may be those who would benefit the most from the default. Examining the new default for consumer checking account overdraft coverage reveals that firms can systematically undermine each of the mechanisms that might otherwise operate to make defaults sticky. Comparing the retirement-savings default to the overdraft default, four boundary conditions on the use of defaults as a policy tool are apparent: policy defaults will not be sticky when (1) motivated firms oppose them, (2) these firms have access to the consumer, (3) consumers find the decision environment confusing, and (4) consumer preferences are uncertain. Due to constitutional and institutional constraints, government regulation of the libertarian-paternalism variety is unlikely to be capable of overcoming these bounds. Therefore, policy defaults intended to protect individuals when firms have the motivation and means to move consumers out of the default are unlikely to be effective unless accompanied by substantive regulation. Moreover, the same is likely to be true of "nudges" more generally, when motivated firms oppose them.

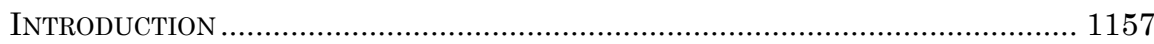

I. What Makes Defaults Sticky? ...................................................... 1161

A. Background Conditions: Confusing Decision Environment and Preference Uncertainty

B. Default Mechanisms: Transaction Barriers .................................. 1163

1. Costs and confusion. ................................................... 1164

2. Invisibility................................................................. 1165

$\dagger$ Robert Braucher Visiting Professor of Law, Harvard Law School; Professor of Law, Loyola Law School, Los Angeles, lauren.willis@lls.edu. For helpful comments, I thank Prentiss Cox, David Driesen, Nicola Howell, Chris Hoofnagle, Peter Huang, Eric Miller, Patricia McCoy, Alexandra Natapoff, Paul Ohm, Jennifer Rothman, Daniel Schwarcz, Eric Talley, Mark Tushnet, and participants at workshops at the University of Colorado Law School, Syracuse University College of Law, the 2013 Annual Meeting of the Association of American Law Schools, and Loyola Law School Los Angeles. I also thank librarian Thomas Boone and research assistants William Bittner, Ryan Jones, and Hillary Thornton. 
C. Default Mechanisms: Judgment and Decision Biases ..................... 1165

1. Loss aversion and the endowment effect.................................. 1166

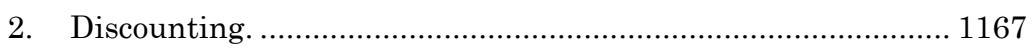

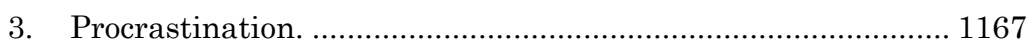

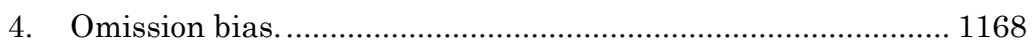

D. Default Mechanisms: Preference Formation …………………....... 1168

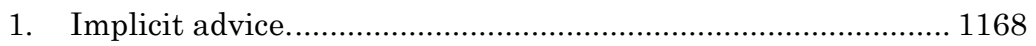

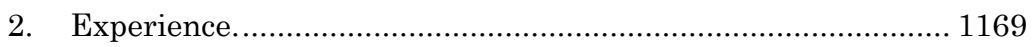

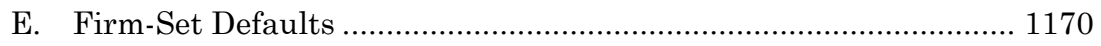

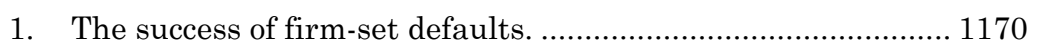

2. Tools used by firms to make defaults sticky............................. 1171

II. WhAT MAKES DEFAULTS SLIPPERY? ......................................................... 1174

A. Anatomy of a Slippery Default: Checking-Account Overdraft........ 1174

1. The policy default................................................................... 1174

2. The law governing opting out...................................................... 1180

3. The limited effects of the policy default.................................... 1181

4. Tools used by banks to make the policy default slippery......... 1185

B. Boundary Conditions on Using Policy Defaults ............................ 1200

1. A sufficiently opposed party................................................. 1200

2. Access to consumers by that opposed party.............................. 1204

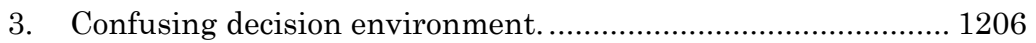

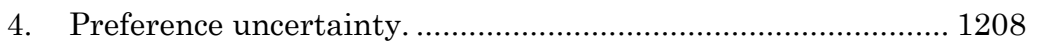

III. Can the Law Make Defaults Sticky . . . But Not Too Sticky? ........... 1211

A. Policy Defaults Must Be Defaults .................................................. 1211

B. Altering Rules (and Complementary Framing Rules) ..................... 1213

1. Prohibit firms from treating consumers in the default

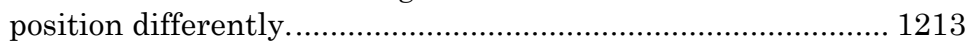

2. Impose transaction barriers that impede opting out. ............... 1214

3. Require consumers to spend time in the default position......... 1216

4. Delay the benefits and expedite contemplation of the costs of

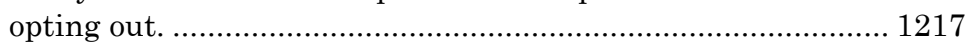

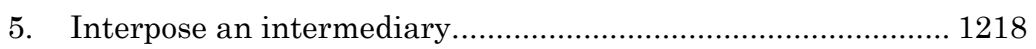

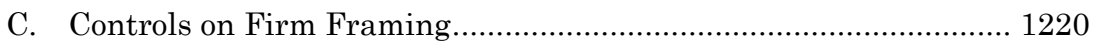

1. Prohibit firm manipulation of judgment and decision biases. 1220

2. Simplify and clarify the decision environment......................... 1222

D. Affirmative Government Framing ................................................. 1224

1. Leverage the opt-out form. ..................................................... 1224

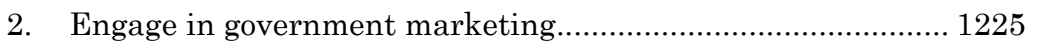

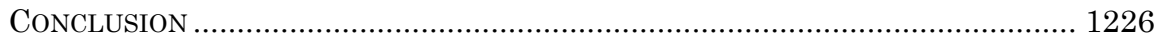




\section{INTRODUCTION}

"Nudging"-framing people's choices so as to channel them to better outcomes without substantively limiting choice-is all the rage,${ }^{1}$ and perhaps the most popular framing tool is the use of policy defaults. ${ }^{2}$ Defaults are settings or rules about the way products, policies, or legal relationships function that apply unless users, affected citizens, or parties take action to change them. Default rules are ubiquitous in the law: intestacy rules that can be overridden by a will, marital property rules that can be overridden by a prenuptial agreement, and gap-filling contract rules that can be overridden by explicit contract language are common examples. But these have largely been put in place because the law needs some rule when the parties have not specified otherwise, rather than with an explicit purpose to alter the ultimate position of the parties. Although many of these defaults are sticky, ${ }^{3}$ that is not their goal. Policy defaults, in contrast, aim for stickiness. ${ }^{4}$ The idea is to set the default to a position that is good for most individuals, under the assumption that only the minority who have clear preferences to the contrary will opt out. 5 The magnetism of defaults is believed to be so strong

\footnotetext{
1 See Richard H. Thaler and Cass R. Sunstein, Nudge: Improving Decisions about Health, Wealth, and Happiness 6 (Yale 2008).

2 "Policy defaults" are defaults put in place by regulators with the explicit goal of increasing the number of people in the default position. See Craig R.M. McKenzie, Michael J. Liersch, and Stacey R. Finkelstein, Recommendations Implicit in Policy Defaults, 17 Psych Sci 414, 414 (2006).

3 See, for example, Omri Ben-Shahar and John A.E. Pottow, On the Stickiness of Default Rules, 33 Fla St U L Rev 651, 670-81 (2006) (providing examples of situations in which default rules are sticky, including revocability of offers and the duration of employment contracts); Russell Korobkin, Inertia and Preference in Contract Negotiation: The Psychological Power of Default Rules and Form Terms, 51 Vand L Rev 1583, 158788 (1998) (explaining that, even in the absence of high transaction costs, the "initial allocation of legal entitlements can affect preferences for those entitlements"). By "sticky," I mean that more people stay in that position than would were it not the default. A "slippery" default is a default that is not sticky, or is less sticky than it was intended to be.

4 When another party has interests contrary to the default, policy defaults might also be characterized as "penalty defaults" from the point of view of that other party. However, the term "penalty defaults" refers to default rules that one or more parties dislike, placed in the law with the aim that the parties would contract around the default. Penalty defaults aim not to be sticky, but to force information revelation and negotiation. See Ian Ayres, Regulating Opt-Out: An Economic Theory of Altering Rules, 121 Yale L J 2032, 2087 (2012).

5 Some proponents emphasize that nudges help people choose what is best for themselves, whereas others emphasize that nudges should encourage people to choose what is best for society (for example, increased organ donation rates). See, for example, Russell Korobkin, Libertarian Welfarism, 97 Cal L Rev 1651, 1653 (2009). This article
} 
that it has been called the "iron law of default inertia."6 Ultimately, nudgers (or "libertarian paternalists"7) claim that defaults and other nudges can easily ${ }^{8}$ and at low cost9 "solve many of society's major problems ... while still insisting on everyone's freedom to choose."10 Unsurprisingly, helping people while dodging the politically perilous explicit tradeoffs and normative judgment calls inherent in substantive regulation is popular with policymakers and academics alike.

The most celebrated, and most cited, example of a policy default is in the area of retirement saving. Although most US employers that offer defined contribution plans wait for employees to sign up on their own, some employers now make participation the default. Employers that have adopted this change in the default rule, commonly called "automatic enrollment," have increased their employee participation rates dramatically. One study found over 85 percent of new hires were participating, nearly double the participation rate before the default was implemented. ${ }^{11}$ The increase has been largest for lower-income consumers, which has been interpreted as evidence that defaults are most helpful for those who need the most help..$^{12}$

largely assumes-as policymakers appear to do-that individual and social welfare are in harmony.

6 Ian Ayres, Menus Matter, 73 U Chi L Rev 3, 4-5 (2006). Ayres has elsewhere recognized that default rules vary in stickiness. See, for example, Ayres, 121 Yale L J at 2084-92 (cited in note 4).

7 Cass R. Sunstein and Richard H. Thaler, Libertarian Paternalism Is Not an Oxymoron, 70 U Chi L Rev 1159, 1160-61 (2003).

8 See Thaler and Sunstein, Nudge at 10 (cited in note 1).

9 See id at 13.

10 Id at 8.

11 See William E. Nessmith, Stephen P. Utkus, and Jean A. Young, Measuring the Effectiveness of Automatic Enrollment, 31 Vanguard Center for Retirement Rsrch *6 (Dec 2007), online at https://institutional.vanguard.com/iam/pdf/CRRAUTO.pdf

?cbdForceDomain=true (visited Sept 11, 2013).

12 See, for example, John Beshears, et al, Public Policy and Saving for Retirement: The Autosave Features of the Pension Protection Act of 2006, in John J. Siegfried, ed, Better Living through Economics 274, 287 (Harvard 2010) (noting "clear and compelling evidence that automatic enrollment was an effective means of increasing savings and improving economic well-being, particularly of minorities and of the poor"); Signe-Mary McKernan and Caroline Ratcliffe, Asset Building for Today's Stability and Tomorrow's Security *4, 7 (Federal Reserve Bank of Boston 2009), online at http://www.urban.org /uploadedpdf/1001374_asset_building.pdf (visited Sept 11, 2013) (listing automatic enrollment in retirement-savings vehicles as one of the policies that would "help lowincome families the most"). This interpretation may be erroneous, as there are some lowincome employees who participate because of automatic enrollment but for whom participation is not optimal. The details of this argument are beyond the scope of this Article. 
Inspired by this apparently unmitigated success, policymakers and regulators have begun to apply policy defaults to other situations where they believe that many people are currently in welfare-decreasing positions and wide majorities would benefit from landing in a different position. The goal is to achieve the retirement savings plan participation effects of automatic enrollment. ${ }^{13}$ In the consumer finance area, legally required default terms have been put in place for checking account overdraft coverage, ${ }^{14}$ credit card over-the-limit practices, ${ }^{15}$ and some home-mortgage escrows. ${ }^{16}$ The Affordable Care Act ${ }^{17}$ uses defaults to increase enrollment in health insurance. ${ }^{18}$ Consumer privacy on the internet appears poised to be the next arena. ${ }^{19}$ More seems sure to follow, given an executive order issued by President Barack Obama requiring all federal agencies to identify and consider implementing regulatory approaches inspired by libertarian paternalism, including "appropriate default rules."20

But how broadly applicable are the results obtained from the retirement savings automatic enrollment default? Evidence from other contexts indicates that policy defaults may not be as effective in increasing welfare as many have hoped, in at least two respects. First, defaults created by the law are not always sticky and can even be slippery. Second, those who opt out are not consistently the ones who are better off outside of the default.

Why are other defaults so much slipperier than automatic enrollment? With respect to the defaults examined here, the key

13 The goal is not merely to inform people about alternatives-a goal which might be met through penalty defaults, see note 4 , or forcing people to make a choice between presented alternatives (called "mandated choice"), see Thaler and Sunstein, Nudge at 86 (cited in note 1).

1412 CFR $\S 205.17$ (prohibiting banks from charging overdraft fees unless the account holder has opted out of the default and into overdraft coverage).

1512 CFR $\S 226.56(b)$ (prohibiting credit card issuers from charging over-the-limit fees, unless the cardholder has opted out of the default and into over-the-limit coverage).

1612 CFR $\S 226.35(b)(3)$ (requiring some home mortgages to be structured so as to escrow for taxes and insurance, but permitting affected borrowers to opt out of this requirement after the first year of mortgage payments).

17 Patient Protection and Affordable Care Act (Affordable Care Act), Pub L No 111148, 124 Stat 119 (2010).

18 See notes $209-10$ and accompanying text.

19 See notes 206-09 and accompanying text.

20 Executive Order 13563, 3 CFR 215, 215-17 (2011) (ordering all federal agencies to consider using a number of nudges, including default rules, when the agencies regulate). 
is whether the interests of the parties are aligned. ${ }^{21}$ In the retirement-savings context, the employer, pension-plan provider, and most employees generally benefit from greater participation rates. But policy defaults have also been established as a means to protect individuals where firms have interests at odds with the default. This matters because, although the popular literature emphasizes the universality of the mechanisms that make defaults sticky, the strength of these mechanisms varies dramatically depending on, for example, the process for opting out and the framing of the default. When firms have significant control over the process for opting out or the context in which the defaults are presented, firms can undermine the stickiness of policy defaults. Further, individuals who generate the most revenue for firms by opting out may be the very people who would benefit most from the default position. Thus, firms may design the opt-out process and surrounding frame not only to make a policy default slippery in general but specifically to encourage those who are worse off outside the default to opt out. In these situations, policy defaults may give the appearance of helping consumers, while doing little more than helping firms defuse political demands for substantive consumer protection.

Part I of this Article examines the mechanisms that make defaults sticky as well as practices that firms use to ensure that those mechanisms are activated when firms set the defaults. Part II provides a case study of a new default explicitly modeled on the retirement savings participation default-the checking account overdraft default. Drawing on data regarding both the overdraft default and other defaults, the Article identifies a nonexhaustive list of boundary conditions for the effective use of policy defaults: an opposed party, access to the consumer by that party, a confusing decision environment, and consumer preference uncertainty.

Part III then explores steps policymakers might take to ensure that policy defaults are not undermined at the implementation stage and finds that a web of surrounding regulation would be needed, including not only rules governing the process by

21 Others have suggested this previously. See, for example, Michael S. Barr, Sendhil Mullainathan, and Eldar Shafir, Behaviorally Informed Financial Services Regulation *4 (New America Foundation Oct 2008), online at http://www.newamerica.net/files /naf_behavioral_v5.pdf (visited Sept 11, 2013); Russell Korobkin, The Status Quo Bias and Contract Default Rules, 83 Cornell L Rev 608, 610 (1998). I substantiate the claim empirically and flesh out boundary conditions on policy defaults here. 
which people can opt out of the default ("altering rules"), ${ }^{22}$ but also rules controlling the manner in which the default is presented ("framing rules"). ${ }^{23}$ The government, however, is not well equipped to control the frame in which people perceive defaults. Regulators might attempt a sophisticated marketing campaign, but firms are more adept at reaching and influencing consumers. Thus, regulation would need to control firm-framing manipulations, a task severely circumscribed by the protections afforded commercial speech under the First Amendment. Further, the altering rules needed to support policy defaults will often have the effect of substantively constraining firm actions and consumer choice, a result at odds with the libertarianpaternalism rationale for using policy defaults in the first place. The Article concludes with a broader lesson about nudging: where a party with the means to influence consumer choice opposes them, government nudges are likely to fail.

\section{What MAKes Defaults STICKY?}

The intellectual and empirical foundation for the belief in the effectiveness of defaults is strong. Research has repeatedly confirmed that, by large margins, people stick with whatever default rule they are handed, more than would choose that position were it not the default. A combination of background conditions and stickiness mechanisms is responsible for this effect. Background conditions that contribute to the traction of defaults are a confusing decision environment and preference uncertainty. The particular mechanisms that give defaults power can be divided into three classes: transaction barriers, judgment and decision biases, and preference formation. ${ }^{24}$ "Transaction barriers" are obstacles to choosing options that reflect preferences, even when options and preferences are easily understood. "Judgment biases" skew perception and appraisal of options. "Decision biases" are reactions to uncertainty about options or preferences. Defaults can also garner adherents through

22 See Ayres, 121 Yale L J at 2036 (cited in note 4); Brett H. McDonnell, Sticky Defaults and Altering Rules in Corporate Law, 60 SMU L Rev 383, 384-85 (2007).

23 See Elizabeth F. Emens, Changing Name Changing: Framing Rules and the Future of Marital Names, 74 U Chi L Rev 761, 840 (2007).

24 Others have conflated these categories, but the taxonomy here seems useful. The implicit-advice mechanism discussed in Part I.D on preference-formation mechanisms, for example, is a conscious process, quite unlike judgment and decision biases, which are unconscious. 
"preference formation," meaning the very process by which preferences are formed. In any particular situation, one or more of these three classes of mechanisms may make defaults powerful for different individuals to varying degrees depending on, for example, how clearly the individual understands her options and her preferences. ${ }^{25}$

\section{A. Background Conditions: Confusing Decision Environment and Preference Uncertainty}

Good decision making requires mapping personal preferences onto available options. Defaults become more powerful as this mapping becomes more difficult, such as when the options are numerous, ${ }^{26}$ have many complex attributes, ${ }^{27}$ or are difficult to distinguish from one another. ${ }^{28}$ Defaults exert a stronger pull over people who only poorly understand their preferences, hold those preferences weakly, or cannot perform the tradeoffs necessary when they have competing preferences. ${ }^{29}$ If people lack information or background knowledge needed to understand their options, defaults are more likely to draw them in. ${ }^{30}$ When people

25 See Jeffrey R. Brown, Anne M. Farrell, and Scott J. Weisbenner, The Downside of Defaults *27 (NBER Working Paper, Sept 2011), online at http://www.nber.org /programs/ag/rrc/NB11-01\%20Brown,\%20Farrell,\%20Weisbenner\%20FINAL.pdf (visited Sept 11, 2013) (finding significant heterogeneity in the reasons people cited for sticking with a retirement-plan default).

26 See, for example, William Samuelson and Richard Zeckhauser, Status Quo Bias in Decision Making, 1 J Risk \& Uncertainty 7, 8 (1988) (describing a series of decisionmaking experiments finding status-quo bias in the face of multiple choices).

27 See, for example, Peter Boxall, W.L. (Vic) Adamowicz, and Amanda Moon, Complexity in Choice Experiments: Choice of the Status Quo Alternative and Implications for Welfare Measurement, 53 Austl J Ag \& Res Econ 503, 513 (2009) (reporting data showing that increasing complexity of choice increases the probability that individuals choose the status quo).

28 See, for example, Ravi Dhar, Consumer Preference for a No-Choice Option, $24 \mathrm{~J}$ Consumer Rsrch 215, 229 (1997) (reporting studies that show consumers may experience an "inability to choose among alternatives that are relatively close in overall attractiveness").

29 See, for example, Korobkin, 51 Vand L Rev at 1622-24 (cited in note 3) (presenting evidence that when preference uncertainty is removed, defaults lose their power); Sarah Lichtenstein and Paul Slovic, The Construction of Preference: An Overview, in Sarah Lichtenstein and Paul Slovic, eds, The Construction of Preference 1 (Cambridge 2006) (observing that judgment and decision biases are strongest when preferences are uncertain); Samuelson and Zeckhauser, $1 \mathrm{~J}$ Risk \& Uncertainty at 8 (cited in note 26) (finding subjects more likely to choose to remain with the status quo when their preferences are weaker).

30 See Brown, Farrell, and Weisbenner, The Downside of Defaults at *33 figure 1 (cited in note 25) (reporting that 28.4 percent of employees who stuck with a retirementplan default stated that one reason they did so was because they lacked information 
have few decision-making resources available with which to consider their preferences and options, such as when they are under high levels of stress or cognitive load, they are more likely to be affected by the mechanisms discussed below and therefore more likely to stick with a default. ${ }^{31}$

A confusing decision environment and preference uncertainty are neither necessary nor sufficient joint conditions for a default to garner more adherents than it would were it not the default. For example, someone might clearly understand an organdonation default but be conflicted about her own preferences. On the one hand, she might feel a social obligation to consent to donating her organs in the event of her death. On the other, she might feel distress at the thought of having her body dismembered after her death. In the face of this conflict, she might procrastinate in making a decision, leaving her in the default position regardless of whether that default is presumed consent or no consent. Another person might have strong privacy preferences, but if she does not know that her information is being shared, she may fail to opt out of an information-sharing default. Even when people can easily map their preferences to their options, they still might stick to a default they would not otherwise favor if the transaction costs outweigh the benefits of opting out. But both a confusing decision environment and preference uncertainty make it more likely that the specific mechanisms described below will affect people's responses when they encounter a default.

\section{B. Default Mechanisms: Transaction Barriers}

Transaction barriers include opt-out costs, confusing opt-out procedures, and invisible opt-out options. These are not what nudgers have in mind, given that they advocate policy defaults on the basis that they do not impede the freedom to opt out. ${ }^{32}$

about their options); id at *17 (finding that lack of background knowledge about investing increases reliance on a retirement-plan default).

31 See, for example, Scott Eidelman and Christian S. Crandall, A Psychological Advantage for the Status Quo, in John T. Jost, Aaron C. Kay, and Hulda Thorisdottir, eds, Social and Psychological Bases of Ideology and System Justification 85, 99 (Oxford 2009).

32 See Thaler and Sunstein, Nudge at 6 (cited in note 1) ("A nudge ... alters people's behavior in a predicable way without forbidding any options or significantly changing their economic incentives. To count as a mere nudge, the intervention must be easy and cheap to avoid.”). 
But in practice, transaction barriers are a common impediment to opting out of defaults.

\section{Costs and confusion.}

The first reason a default might be sticky relates to the process for opting out, also called the altering rule. Altering rules make defaults sticky in two ways: by imposing actual or perceived costs and/or by creating confusion. To the extent that opting out of a default imposes actual costs that exceed the benefits to be gained by switching, accepting the default could be a conscious and rational response. Even the smallest transaction cost can make a default stick if the individual does not expect any benefit. An employee who does not expect to remain with an employer long enough for her retirement savings to vest will not bother to opt out of a noncontribution default. ${ }^{33}$ But transaction costs can also be misperceived, and it is perceptions that matter here. For example, a computer novice might assume that downloading and installing a new internet browser will be time consuming and technically difficult, when in fact the process is quick and almost entirely automated.

The process for opting out can also be confusing, leading some people to accidentally and unknowingly stick with defaults. A prime example is the process for opting out of online information-sharing defaults. When a sample of well-educated internet users with concerns about online privacy were observed using various tools for opting out of default internet tracking settings, none were able to opt out to the extent that they desired. ${ }^{34}$ Moreover, most believed that they had opted out when they had not. For example, subjects switched the setting for Internet Explorer 9's "Tracking Protection" add-on from "disabled" to "enabled" and assumed that this meant they had opted out of being tracked. But the opt-out process actually requires a further

33 See Brown, Farrell, and Weisbenner, The Downside of Defaults at *20 (cited in note 25) (reporting study results showing that 13.4 percent of participants remained in the default retirement plan because they did not expect to work at the company for long enough to vest in the plan).

34 See Pedro G. Leon, et al, Why Johnny Can't Opt Out: A Usability Evaluation of Tools to Limit Online Behavioral Advertising *20 (Carnegie Mellon University CyLab Oct 31, 2011), online at http://www.cylab.cmu.edu/files/pdfs/tech_reports/CMUCyLab11017.pdf (visited Sept 11, 2013). 
step of creating a personalized "Tracking Protection List" that lists the websites to block. ${ }^{35}$

\section{Invisibility.}

Another transaction barrier relates to the framing of the default. When the choice to opt out of a default is not made plain, people may perceive a default as unchangeable. ${ }^{36}$ This is likely to be the case in unfamiliar task environments. For example, many people stick with the default settings on their computer-software programs, despite the ability to customize these, in part because they do not know that users can change these settings. ${ }^{37}$ But if another party has the means and motive to switch the default, a user could accept the new position through inertia. ${ }^{38} \mathrm{~A}$ novice computer user at home might accept the manufacturer's settings; a novice user at work might accept different settings selected by her employer.

\section{Default Mechanisms: Judgment and Decision Biases}

The second class of reasons for defaults' magnetism, and the one most nudgers have in mind given their behavioral economics roots, is judgment and decision biases. Foremost, supporters of defaults intend to harness the "status quo effect," an umbrella term for the various biases that cause inertia regardless of whether this is the best course. ${ }^{39}$ Each of the following contributes to the status quo effect. ${ }^{40}$ Key to each is the frame in which the default is perceived, as explained below.

\footnotetext{
35 See id at *10 table 1, 30 figure 13 (noting difficulties that a study's participants had using the blocking tool "IE-TPL").

36 See, for example, Brown, Farrell, and Weisbenner, The Downside of Defaults at *33 figure 1 (cited in note 25) (reporting that 19 percent of employees who stuck with a retirement plan default stated that they did so because they did not know they could opt out).

37 See Jessamyn C. West, Without a Net: Librarians Bridging the Digital Divide 21 (Libraries Unlimited 2011).

38 See Korobkin, 51 Vand L Rev at 1605-09 (cited in note 3) (noting that, although a default rule can be the position favored by inertia, inertia can also favor any position an actor finds herself in).

39 See Samuelson and Zeckhauser, $1 \mathrm{~J}$ Risk \& Uncertainty at 33-42 (cited in note 26).

40 In addition to the judgment biases listed here, the process of anchoring and adjustment can create what has been dubbed the "default pull." Where choices include a range of possible values, this process can lead people to select not the default, but a choice closer to the default than they would otherwise choose. See Nikhil Dhingra, et al, The Default Pull: An Experimental Demonstration of Subtle Default Effects on Preferences, 7 Judgment \& Dec Making 69, 75 (2012) (reporting evidence that defaults pull
} 
1. Loss aversion and the endowment effect.

Defaults may be powerful due to biases in weighing the costs and benefits of moving away from the default. Loss aversion, meaning weighting losses more heavily than gains as against some reference point, can come into play when losses and gains are not in a commensurate currency. ${ }^{41}$ One explanation for this, called "query theory," is that people generate more answers to the first question they ask themselves than the second, and they routinely ask themselves about the benefits of the reference point before considering an alternative position. ${ }^{42}$ To the extent that the default position is framed as the reference point, loss aversion biases the decision in favor of the default.

One manifestation of loss aversion is the "endowment effect"-placing a higher value on what one already possesses (or perceives oneself as possessing) than on the same thing when one does not possess it. ${ }^{43}$ The endowment effect occurs because possession of the good or position becomes the reference point against which loss is measured. ${ }^{44}$

decision maker choices closer to the default position than these choices would otherwise be, even though the decision maker does not choose the default option itself). Because the default choices examined in this Article are all binary-one is either in the default position or not in the default position-anchoring and adjustment are not relevant here.

41 See Nathan Novemsky and Daniel Kahneman, The Boundaries of Loss Aversion, 42 J Mktg Rsrch 119, 123-24 (2005).

42 See, for example, Isaac Dinner, et al, Partitioning Default Effects: Why People Choose Not to Choose, 17 J Exp Psych: Applied 332, 333 (2011) (explaining and providing evidence for this "Query Theory" for loss aversion); Kirstin C. Appelt, et al, Time to Retire: Why Americans Claim Benefits Early and How to Encourage Delay *39 (unpublished conference paper, Exploring New Frontiers in Financial Capacity for Vulnerable Populations Workshop, UW-Madison Center for Financial Security, June 5-6, 2012), online at http://financialcapability.files.wordpress.com/2012/03/eric-johnson.pdf (visited Sept 11, 2013) (finding that query order strongly encouraged subjects to prefer the first alternative considered).

43 See Richard Thaler, Toward a Positive Theory of Consumer Choice, $1 \mathrm{~J}$ Econ Beh \& Org 39, 44 (1980) (coining the term "endowment effect" and reporting experimental evidence of its existence). The exposure effect has a similar result through a different path. When people are exposed to something and are not harmed in the process, they prefer it over something to which they have not been exposed. See, for example, Robert B. Zajonc, Attitudinal Effects of Mere Exposure, $9 \mathrm{~J}$ Personality \& Soc Psych Monograph Supp 1, 13 (1968).

44 See Russell Korobkin, Wrestling with the Endowment Effect, or How to Do Law and Economics without the Coase Theorem, in Eyal Zamir and Doron Teichman, eds, Oxford Handbook of Behavioral Economics and the Law (Oxford forthcoming). 


\section{Discounting.}

A more significant default effect would be likely where the perceived upfront costs of opting out are immediate and certain, whereas the perceived benefits are uncertain and/or in the distant future, due to excessive discounting over time and uncertainty. ${ }^{45}$ Discounting over time and uncertainty probably plays a large role in the magnetism of the still-common default retirement savings contribution rate of zero. Saving for retirement means a certain loss of current income. The benefits are in the future and, given the unpredictable performance of most retirement investments, often uncertain. Rather than trading the upfront certain loss for an uncertain future gain, employees stick with the default. The same may be true for many healthprotective behaviors - the costs of taking a run in the rain today are immediate and certain, whereas the health benefits are uncertain and in the future, leading people to stay in the proverbial couch-potato default position.

\section{Procrastination.}

Different causal mechanisms may be at play when the decision is perceived as difficult to make or as involving high stakes. Anticipated cognitive or emotional difficulty can lead to procrastination in engaging in the research and deliberation people would like to apply to the decision, and then a failure to make any decision. ${ }^{46}$ For example, increasing the number of investment options in a pension plan makes allocating savings among the options more cognitively challenging for many employees and leads more employees to stick with the default allocation. ${ }^{47}$ Even when options are few, when decision makers find tradeoffs among choices challenging, they gravitate towards the default

45 See Yaacov Trope and Nira Liberman, Construal-Level Theory of Psychological Distance, 117 Psych Rev 440, 451-53 (2010) (explaining the tendency for people to discount over psychological distance, including over time and over uncertainty).

46 See Ted O'Donoghue and Matthew Rabin, Choice and Procrastination, 116 Q J Econ 121, 122 (2001) (explaining why high stakes can lead to procrastination). See also Brown, Farrell, and Weisbenner, The Downside of Defaults at *33 figure 1 (cited in note 25) (reporting that 37.9 percent of employees who stuck with a retirement-plan default stated that they did so because they never got around to making a choice).

47 See Sheena Sethi-Iyengar, Gur Huberman, and Wei Jiang, How Much Choice Is Too Much? Contributions to 401(k) Retirement Plans, in Olivia S. Mitchell and Stephen P. Utkus, eds, Pension Design and Structure: New Lessons from Behavioral Finance 83, 88-91 (Oxford 2004). 
status quo. ${ }^{48}$ An example previously discussed is organ donation. The conflict some people feel about whether to be an organ donor in the event of death may contribute to the magnetism of both presumed consent and no-consent organ donation defaults. ${ }^{49}$

\section{Omission bias.}

Fear of making the wrong decision can also give defaults traction due to omission bias and regret aversion. People are more likely to blame themselves and experience regret about a poor outcome when they make an active decision to leave a default (an error of commission) than when the outcome is caused by having remained with the default (an error of omission). ${ }^{50}$ They stick with the default to avoid potential self-blame, a phenomenon dubbed "omission bias." For example, some parents who know that a failure to vaccinate is riskier than vaccination still choose to remain with the default to avoid the smaller risk inherent in the action of getting their children vaccinated. ${ }^{51}$ Omission bias leads these parents to stick with the inaction default. They will not take an action (vaccination) that could put their children at risk even though their inaction (failure to vaccinate) places the children at greater risk.

D. Default Mechanisms: Preference Formation

A third driver of stickiness is the way in which people use defaults to form their own preferences.

1. Implicit advice.

People sometimes treat defaults as a form of implicit advice. ${ }^{52}$ This is particularly likely when the party that has chosen the default is perceived as having the individual's or society's best interests in mind, such as the government or an employer.

48 See, for example, Samuelson and Zeckhauser, 1 J Risk \& Uncertainty at 31-33 (cited in note 26).

49 See Carmen M. Radecki and James Jaccard, Psychological Aspects of Organ Donation: A Critical Review and Synthesis of Individual and Next-of-Kin Donation Decisions, 16 Health Psych 183, 186-87 (1997).

50 See Jonathan Baron and Ilana Ritov, Reference Points and Omission Bias, 59 Org Beh \& Hum Dec Processes 475, 478 (1994).

51 See David A. Asch, et al, Omission Bias and Pertussis Vaccination, 14 Med Dec Making 118, 120-21 (1994).

52 See McKenzie, Liersch, and Finkelstein, 17 Psych Sci at 416-17 (cited in note 2) (finding that people believe defaults reflect what the person who set the default thinks is best for them). 
For example, some employees interpret an employer's selection of default employee-benefit levels as the employer's endorsement ${ }^{53}$ or assessment of what most employees want. ${ }^{54}$ Along these same lines, individuals may perceive the default as representing the most popular choice (as opposed to the default leading to the most popular choice) and select it due to faith in the wisdom of others or a desire to conform to perceived social norms. ${ }^{55}$ In reality, default settings may have been mandated by law, selected by self-interested benefits providers, or set long ago based on now-outdated information. But unless people know otherwise, they may assume that defaults have been consciously and benevolently chosen by someone with more expertise than they possess.

\section{Experience.}

Although not what nudging proponents have in mind, when preexisting preferences are uncertain, defaults could also be powerful in forming preferences through experience. ${ }^{56}$ If the opportunity to opt out of the default is presented after the decision maker has spent some time in the default position, not only might the transaction costs of change be high-and loss aversion, the endowment effect, and omission bias kick in-but the decision maker might have developed a new preference in favor of the default. ${ }^{57}$ That is, the decision maker might try it and like it. Yet if a different default had been selected, the decision maker might have been just as likely to form a preference in favor of

53 See Brown, Farrell, and Weisbenner, The Downside of Defaults at *33 figure 1 (cited in note 25) (reporting that 20 percent of employees who stuck with their employer's retirement-plan default stated that one reason they did so was they believed their employer had endorsed the default).

54 See McKenzie, Liersch, and Finkelstein, 17 Psych Sci at 416-17 (cited in note 2) (finding that people believe defaults reflect what the person who set the default believes most people want).

55 See Thaler and Sunstein, 93 Am Econ Rev at 177 (cited in note 7). Faith in the wisdom of others has been dubbed "social proof." Robert B. Cialdini, Influence: Science and Practice 100 (Allyn and Bacon 4th ed 2001).

56 Nudge emphasizes that defaults should be set to what a person who had rationally reflected on the choice would select. Thaler and Sunstein, Nudge at 12 (cited in note 1). This implies that the default would reflect existing preferences rather than cause preferences to change.

57 Distinguishing between the influence of judgment biases that affect the evaluation of choices and the preference-forming effects of experience may not be possible, but it seems that more than biases cause people to prefer what they know over what they do not know. 
that default. ${ }^{58}$ The effect is similar to that of a free sample. For example, many internet browsers and mobile devices come with preinstalled, default bookmarks. Although the bookmarks can often be easily removed, firms pay to have them preinstalled. These firms know that consumers are more likely to navigate to sites that have been bookmarked and that some of these consumers will, through experience, like what they find there.59

\section{E. Firm-Set Defaults}

1. The success of firm-set defaults.

Firms regularly employ defaults to achieve desired outcomes. Not all defaults benefit firms directly, and many benefit consumers at the same time. Products often are sold with maximally safe settings as the default, shielding consumers from physical injury and manufacturers from injury to reputation and product-defect liability. ${ }^{60}$ But some firm-set defaults provide benefits to firms and potential costs to consumers. Autorenewal of subscriptions, insurance automatically sold with car rentals, default mailing list sign-ups, and prechecked "options" added to online purchases are all common examples. As explained by an assistant managing editor at The New York Times, the paper was able to raise its home-delivery price by 5 percent during the recession while retaining 99.99 percent of its subscribers due to the default effect of credit card autorenewal payments: "We have north of 800,000 subscribers paying north of $\$ 700$ a year for home delivery. ... I think a lot of it has to do with the fact that

58 See William G. Gale, et al, Increasing Annuitization in 401(k) Plans with Automatic Trial Income, Retirement Security Project Report No 2008-2 10-11 (Retirement Security Project 2008), online at http://www.brookings.edu/ /media/Files/rc/papers /2008/06_annuities_gale/06_annuities_gale.pdf (visited Sept 11, 2013) (suggesting that biases that discourage retirees from annuitizing their savings upon retirement could be counteracted by defaulting them into annuitization, with an option to opt out, and explaining that by trying annuitization for two years, retirees would discover through experience whether they like it).

59 See, for example, Frequently Asked Questions (Opera Software 2013), online at http://www.opera.com/company/investors/faq/\#faq3 (visited Sept 11, 2013) (explaining that one of the ways the Opera browser generates revenue is through fees paid by companies for integrated search and shopping bars).

60 See Restatement (Third) of Torts § 2, comment a (1998). 
they're literally not understanding what they're paying.... That's the beauty of the credit card."61

Given the power of defaults to attract business, controlling the default can be extremely valuable. When landline telephone companies position their optional wire-maintenance plan as a service to which consumers must subscribe, 44 percent of consumers do so; when the companies position the service as part of the default package from which consumers must unsubscribe, over 80 percent of consumers buy it. ${ }^{62}$ Google spends hundreds of millions of dollars to be the default search engine on web browsers, and browser-owning firms pay to have their browser be the default preloaded on computers. ${ }^{63}$

2. Tools used by firms to make defaults sticky.

Firms actively work to increase the power of their defaults using each of the three classes of mechanisms described abovetransaction barriers, judgment and decision biases, and preference formation. By surrounding their defaults with a web of carefully selected altering rules and framing devices, firms aim to catch any consumer who might otherwise escape the default.

Firms ensure that the altering rule-the process for opting out of the default-bolsters the default. ${ }^{64}$ For example, firms with automatically renewing subscriptions that consumers can sign up for in minutes online may require spending an hour on hold with customer service to cancel.65 Firms stymie consumers who might attempt to opt out, using fine print or confusing

61 Jeff Bercovici, NY Times Editor on the 'Beauty' of Readers' Ignorance (Forbes Nov 10, 2010), online at http://www.forbes.com/sites/jeffbercovici/2010/11/10/ny-times-editor -on-the-beauty-of-readers-ignorance (visited Sept 11, 2013).

62 See Jeff Sovern, Opting In, Opting Out, or No Options at All: The Fight for Control of Personal Information, 74 Wash L Rev 1033, 1092 \& n 284 (1999) (describing the results of a Federal Communications Commission study).

63 See Steve Lohr, The Default Choice, So Hard to Resist, NY Times BU5 (Oct 16, 2011).

64 See, for example, Sovern, 74 Wash L Rev at 1085-87 (cited in note 62) (detailing ways in which firms use invisibility, costs, and confusion to deter consumers from opting out of defaults that allow firms to collect and use personal consumer information).

65 See, for example, Kara Rowland, Customers Say XM Didn't Let Them Go without a Fight, Wash Times A1 (June 20, 2007), online at http://www.washingtontimes.com /news/2007/jun/20/customers-say-xm-didnt-let-them-go-without-a-fight/?page=all (visited Sept 11, 2013) ("It took more than two weeks, five phone calls, numerous e-mails ... and ultimately a formal complaint to our state attorney general to have our subscriptions canceled as requested."). 
websites as transaction barriers. ${ }^{66}$ Or they revert consumers to the default, requiring consumers to opt out repeatedly. ${ }^{67}$

Firms exacerbate judgment and decision biases intentionally through framing devices. They advertise the benefits of the default, 68 both to directly shape preferences and so that consumers will consider the benefits of the default before considering any alternatives, thereby leveraging the query-theory process that may drive loss aversion and thus the default. They increase the difficulty of decisions to foster procrastination, thereby encouraging use of the default. For example, the 50 privacy buttons and 170 options Facebook users must wade through in the course of rejecting the website's preset privacy defaults appear designed to encourage sticking with the default rather than to respond to user demand for all 170 options. ${ }^{69}$ Firms play on omission bias, warning users that if a user takes an affirmative action to change the default, the user and not the firm will be responsible for the results. ${ }^{70}$

66 See, for example, Ben Popken, RyanAir Hides Travel Insurance Opt-Out under "Country of Residence" Drop-Down (Consumerist Sept 17, 2010), online at http://consumerist.com/2010/09/ryanair-hides-travel-insurance-opt-out-under-country-of -residence-drop-down.html (visited Sept 11, 2013) (demonstrating how an airline's website leads consumers to unwittingly accept the firm's default travel insurance when they buy a plane ticket because the opt-out choice is hidden behind a drop-down menu); Debbie Timmins, How to Turn Off Xbox Live Auto-Renewal Online! (Average Gamer Oct 21, 2010), online at http://www.theaveragegamer.com/2010/10/21/how-to-turn-off-xbox-live -auto-renewal-online (visited Sept 11, 2013) (explaining how Microsoft has hidden the link that must be clicked to stop Xbox Live from automatically renewing).

67 See, for example, Nick Wingfield, Microsoft Quashed Effort to Boost Online Privacy, Wall St J (Aug 1, 2010), online at http://online.wsj.com/article /SB10001424052748703467304575383530439838568.html (visited Sept 11, 2013) (describing how Microsoft's Internet Explorer 8.0 browser defaults to a setting by which advertisers can track users' online browsing, and although users can opt out of the default, they must do so every time they start up the software); Ben Popken, Call Every Time to Make Sure Extra Payments Go to Paying Down Principal (Consumerist May 3, 2011), online at http://consumerist.com/2011/05/03/call-every-time-to-make-sure-extra-payments -go-to-paying-down-principal (visited Sept 11, 2013) (reporting one bank that, by default, applies any payment on a mortgage beyond the amount due to future interest rather than the principal and requires borrowers who want to pay down the principal to call in every month to request a change in the way the payment is applied).

68 See, for example, IBM Software Subscription and Support (IBM), online at http://www-01.ibm.com/software/lotus/passportadvantage/softwaremaintenance.html (visited Sept 11, 2013) (describing the benefits of automatically renewing subscription to IBM software support, which is the default).

69 See Nick Bilton, Price of Facebook Privacy? Start Clicking, NY Times B8 (May 13, 2010).

70 For example, typing "about:config" into the location bar on the Firefox browser brings up a dialog box warning users attempting to make changes to the browser's 
Firms attempt to shape consumer preferences to favor the default. They trumpet the benefits and downplay the costs of the default. They explicitly tell consumers that a default is "recommended" or "advised." 71 For example, Facebook dubs its widely criticized default privacy settings "recommended." 72

In affirmatively nurturing the conditions and mechanisms that push consumers towards the default, firms implicitly acknowledge that defaults, per se, are not necessarily all that powerful. It is the combination of a default, opt-out process, and framing that is collectively powerful.

Experimental evidence supports this conclusion. Subjects were given a choice marked as the default and a nondefault option under the following conditions: The process for opting out was easy, costless, and obvious, so costs, confusion, and invisibility were not present. The subjects spent no time in the default position prior to a decision, so loss aversion, the endowment effect, and preference formation through experience could not come into play. Discounting did not favor the default over opting out. The decision had to be made during the experiment, meaning neither procrastination nor inaction to avoid regret were possible. Finally, subjects had no reason to think that the default might convey advice. Under these conditions, the default had little or no effect on subjects' choices.73 The lesson for policy defaults is clear: to draw people to the default, the conditions must exist or be created that trigger the mechanisms that make defaults sticky.

default settings: "This might void your warranty! . . You should only continue if you are sure of what you are doing."

71 For example, computer software programs often come with "recommended" default installation settings. See, for example, Wifi Network (2009), online at http://support.wmwifirouter.com/documentation/57/Wifi_network (visited Sept 11, 2013) ("The default and advised setting for this is 1, and you should not change it unless you know what you are doing.").

72 See Dave Taylor, Recommended Facebook Privacy Settings: Everyone? (The Business Blog at Intuitive.com June 2, 2010), online at http://www.intuitive.com/blog /recommended_facebook_privacy_settings_everyone.html (visited Sept 11, 2013); Kevin Bankston, Facebook's New Privacy Changes: The Good, the Bad, and the Ugly, Deeplinks Blog (Electronic Frontier Foundation Dec 9, 2009), online at https://www.eff.org/deeplinks/2009/12/facebooks-new-privacy-changes-good-bad-and-ugly (visited Sept 11, 2013).

73 See Julie R. Agnew, et al, Who Chooses Annuities? An Experimental Investigation of the Role of Gender, Framing and Defaults, 98 Am Econ Rev 418, 421 (2008). 


\section{WHAT MAKES DEFAULTS SLIPPERY?}

As demonstrated by the foregoing discussion of firm-set defaults, the power of a default can be enhanced by manipulating the opt-out process and the context surrounding the default to increase the likelihood that the mechanisms that make defaults sticky will be triggered. However, as shown below, the opt-out process and the framing of a default can instead be designed so as to decrease a default's power. When a party opposes a policy default imposed by the law, that party can minimize transaction barriers so that these will not bolster the default, and can even erect transaction barriers that favor opting out. An opposed party can not only remove the conditions that trigger judgment and decision biases that lead consumers to default positions, but can even create conditions that trigger these biases to lead consumers to opt out. To further encourage opting out, a party can attempt to directly shape people's preferences. The law often places some altering and framing rules in the way of opting out of policy defaults. But parties implementing those rules may be able to shape the process for opting out and the context in which people encounter the default so as to comply with the letter of the law while undermining the law's aim for stickiness.

A. Anatomy of a Slippery Default: Checking-Account Overdraft

1. The policy default.

One of the latest attempts by regulators to harness the power of a default is the case of checking account overdraft coverage for automated teller machine (ATM) and nonrecurring debit card transactions. An overdraft occurs when an account holder unintentionally or intentionally attempts to withdraw more from his or her checking account than is available in the account and the bank ${ }^{74}$ covers the withdrawal with its own funds, meaning the account may go to a negative balance. Prior to the imposition of this policy default, the practice of most banks was to allow, at the bank's discretion, all types of transactions (ATM, debit, and check transactions, among others) to overdraw an account, for a fee. Under the new regulation, which came into effect in $2010,{ }^{75}$ banks cannot charge a fee for checking-account

\footnotetext{
74 I use the colloquial term "bank" to refer to any financial institution that offers checking accounts.

7512 CFR $§ 205.17(\mathrm{c})$.
} 
overdrafts occasioned by ATM or nonrecurring debit card transactions unless the account holder has opted out of the policy default and into the bank's overdraft coverage for these types of transactions. ${ }^{76}$ The policy default does not speak to occasions when a check or a scheduled recurring payment overdraws an account, and most banks cover these overdrafts for a fee, at the bank's discretion.

Overdraft coverage is, in effect, a low-risk, high-cost loan. Banks face little risk that these loans will not be repaid for two reasons. First, banks use their discretion to allow overdrafts only when the account holder is making regular deposits and in fact deny about one-third of transactions that would overdraw a customer's account. 77 Second, banks take the next deposit into the account to immediately repay the amount overdrawn and the fee, without giving account holders an opportunity to divert the funds to other purposes. ${ }^{78}$

Yet the price charged to consumers for overdraft coverage is relatively high in relation to the amount borrowed. Among banks studied by the FDIC in 2006, the median negative balance from a debit transaction on which an overdraft fee was charged was about $\$ 20,{ }^{79}$ and the median fee was $\$ 27 .{ }^{80}$ Larger

$76 \quad 12$ CFR $§ 205.17$.

77 See, for example, Chase Debit Card Coverage *1 (Chase 2011), online at https://chaseonline.chase.com/resources/Chase_Opt_In_Branch_Flyer_v6.pdf (visited Sept 11, 2013) ("[W] typically do not pay overdrafts if your account is not in good standing, or you are not making regular deposits."); Helpful Tips on Managing Your Account (M\&T Bank 2013), online at https://www.mtb.com/personal/loanscredit /OverdraftProtection/ManageMyAccount/Pages/Managing-Your-Account.aspx (visited Sept 11, 2013) (reserving the right to deny transactions that would overdraft an account); Frequently Asked Questions (TD Bank 2013), online at http://www.tdbank.com/popup/TDAFAQ.html (visited Sept 11, 2013) ("TD Bank FAQ") (same). See also 12 CFR $§ 205.17(b)(3)$ Supp I (noting that banks retain discretion to deny transactions that overdraw an account even if the consumer has opted out of the policy default); Ron Lieber and Andrew Martin, Overspending on Debit Cards Is Painful, but Not for Banks, NY Times A20 (Sept 9, 2009).

78 See Center for Responsible Lending, Consumer Federation of America, and National Consumer Law Center, Comments to the Consumer Financial Protection Bureau, Docket No CFPB-2012-0007, 77 Fed Reg 12031 (Feb 28, 2012): Impacts of Overdraft Programs on Consumers *3 (Consumer Federation of America June 29, 2012), online at http://www.consumerfed.org/pdfs/Comments.CFPB.Overdraft.CRL.CFA\%20.NCLC6.29 .12.pdf (visited Sept 11, 2013) (reporting various bank overdraft practices and listing recommendations for improvements).

79 See Patricia Cashman, et al, FDIC Study of Bank Overdraft Programs v (FDIC Nov 2008), online at http://www.fdic.gov/bank/analytical/overdraft/FDIC138_Report

_Final_v508.pdf (visited Sept 11, 2013) ("FDIC Study") (reporting that the median dollar amount of debit-overdraft transactions was $\$ 20$ and that these were the most frequent transactions). 
institutions charged more, ${ }^{81}$ leading to the "\$35 cup of coffee" familiar in media reports about overdraft. ${ }^{82}$ Because each transaction that overdraws an account may trigger a fee, an account holder who buys a cup of coffee at one store, groceries at another, hardware from a third, and so on can incur multiple fees in a single day, potentially accruing into the hundreds of dollars. ${ }^{83}$ For those who do not repay their overdrafts and associated fees, the ultimate price is loss of checking-account privileges; an unpaid overdraft is the most common reason for an involuntarily closed account, and other institutions normally will not open a new account for someone with a history of an involuntarily closed account. 84

The price of overdraft coverage is also relatively high as compared to other forms of short-term credit. A common fee structure is to require overdrawn account holders to bring their account balance back to zero within a week or face a "sustained" overdraft fee. ${ }^{85}$ A $\$ 27$ fee on what is in effect a loan of $\$ 20$ for seven days translates to an annual percentage rate (APR) of over 7,000 percent. ${ }^{86}$ In contrast, the average APR on a credit card for a cash advance about this time period was under 30

80 See id at 15.

81 See id.

82 See, for example, Editorial, That $\$ 35$ Cup of Coffee, NY Times A22 (Nov 14, 2009).

83 See Lieber and Martin, Overspending on Debit Cards, NY Times at A1 (cited in note 77) (telling the story of a consumer who had deposited a check that had not yet cleared and then bought a cup of coffee, a few screws, a movie ticket, and other items, and ended up with $\$ 238$ in overdraft fees that day); Board of Governors of the Federal Reserve System, Electronic Fund Transfers, 74 Fed Reg 59033, 59038 (2009) (final rule; official staff commentary) (noting that account holders can incur hundreds of dollars of fees in one day).

84 See Dennis Campbell, F. Asís Martínez-Jerez, and Peter Tufano, Bouncing Out of the Banking System: An Empirical Analysis of Involuntary Bank Account Closures, $36 \mathrm{~J}$ Bank \& Fin 1224, 1224 (2012). In addition, over 8 percent of consumers who have voluntarily closed their bank accounts explain that they have chosen to be unbanked so as to avoid overdraft and bounced-check fees. Michael Bachman, et al, FDIC National Survey of Unbanked and Underbanked Households *26 figure 4.13 (FDIC Dec 2009), online at http://www.fdic.gov/householdsurvey/2009/full_report.pdf (visited Sept 11, 2013).

85 The number of days the overdraft can remain outstanding before a "sustained overdraft fee" kicks in varies from three to ten days. See Chris Friedrich, The High Cost of Opting In to Overdraft Fees (CreditCards.com Sept 13, 2010), online at http://www.creditcards.com/credit-card-news/overdraft-fees-opt-in-credit-card-act-1282.php (visited Sept 11, 2013).

86 The APR can be calculated by multiplying the amount of the fee by the proportion of one year for which the sum is borrowed, divided by the sum borrowed, multiplied by 100 . Here, the calculation would be $\$ 27 \times(365 / 7) / \$ 20 \times 100=7,039 \%$. 
percent. ${ }^{87}$ Further, many banks offer less expensive ways to pay for transactions that would otherwise overdraw an account: opening an "overdraft line of credit" or linking a checking account to a savings or credit card account. In 2006, the typical charge for the former was 18 percent APR and for the latter was a $\$ 5$ flat funds-transfer fee (plus, if applicable, any fees charged by the card issuer). 88

Why are banks able to charge high fees for overdraft coverage? Internal bank documents explain that those who incur overdraft fees do not expect to overdraw their accounts, and therefore neither arrange for lower-cost ways to cover transactions that will overdraw their accounts nor shop for checking accounts with the lowest overdraft fees. ${ }^{89}$ Banks therefore have no competitive incentive to reduce overdraft fees to cost.

Consequently, overdraft coverage is quite lucrative for banks. In 2009, US consumers spent an estimated $\$ 20$ billion on overdraft fees occasioned by ATM or debit transactions. ${ }^{90}$ Among banks studied by the FDIC in 2006, overall overdraft fees amounted to about 75 percent of bank deposit account service charges revenue and 25 percent of total bank noninterest income. ${ }^{91}$ As the banking industry has frankly explained, these fees exceed the cost of providing overdraft coverage and instead subsidize much of the cost of "free" checking accounts. ${ }^{92}$

\footnotetext{
87 See Government Accountability Office, Credit Cards: Credit Cards-Increased Complexity in Rates and Fees Heightens Need for More Effective Disclosures to Consumers, GAO-6-929, 18 (Sept 2006), online at http://www.gao.gov/new.items/d06929.pdf (visited Sept 11, 2013) (finding, among the most popular cards from major issuers in 2005, cash advance APRs were "around 20 percent on average").

88 Cashman, et al, FDIC Study at iii (cited in note 79).

89 See Mark Armstrong and John Vickers, Consumer Protection and Contingent Charges, 50 J Econ Lit 477, 480 \& n 13 (2012), citing Office of Fair Trading, Personal Current Accounts in the UK: An OFT Market Study *4 (UK Office of Fair Trading July 2008), online at http://www.oft.gov.uk/shared_oft/reports/financial_products/OFT1005.pdf (visited Sept 11, 2013).

90 See Andrew Martin and Ron Lieber, Overdraft Open Season, NY Times B1 (Feb $23,2010)$ (reporting that industry consultant Michael Moebs estimated that $\$ 20$ billion in bank revenue from ATM and nonrecurring debit transaction overdrafts occurred in 2009).

91 Cashman, et al, FDIC Study at 56 (cited in note 79) (reporting a 2006 study's findings that overdraft charges accounted for 74.4 percent of total service charges on deposit accounts and 24.8 percent of the total noninterest income earned in sample banks). See also id at 62 (reporting a low level of checking-account charge offs, meaning that the vast majority of overdrafts and associated fees are repaid by account holders).

92 See 74 Fed Reg at 59039 (noting that the banking industry, in opposing the overdraft policy default, argued that, because overdraft fees subsidize checking-account maintenance costs, any loss of overdraft revenue would harm consumers who currently enjoy checking-account services without paying for them).
} 
Although overdraft fees subsidize all checking accounts, they are incurred by a small subset of consumers. In 2006, at banks studied by the FDIC, an estimated 75 percent of account holders never overdrew their accounts, 12 percent overdrew their accounts only infrequently, and the 14 percent of bank customers who overdrew their accounts five or more times per year incurred over 90 percent of all overdraft fees. ${ }^{93}$ This last group was disproportionately minority and low income. ${ }^{94}$ In 2009 , one widely cited industry consultant estimated that 90 percent of overdraft fees were paid by the poorest 10 percent of checkingaccount holders. ${ }^{95}$ Because these fees effectively subsidize all checking accounts, the effect is that the poorest account holders pay the costs of all accounts.

In issuing the 2010 overdraft rules, banking authorities cited a number of motivations for using this new policy default, including:

- a desire to prevent consumers who frequently overdraw their accounts from "entering into a harmful cycle of repeated overdrafts"; 96

- concern for the costliness of overdraft coverage, particularly in relation to the amount borrowed; 97

- consumers' stated preference to have ATM and debitcard overdrafts declined rather than incurring a fee; 98 and

- behavioral research suggesting that consumers are likely to overoptimistically assume they will not overdraw their accounts. ${ }^{99}$

\footnotetext{
93 Cashman, et al, FDIC Study at iv (cited in note 79).

94 See Leslie Parrish and Josh Frank, An Analysis of Bank Overdraft Fees: Pricing, Market Structure and Regulation, 45 J Econ Issues 353, 357 (2011) (referencing findings that low-income and minority consumers are more likely than the general population to have overdrawn their checking accounts); Cashman, et al, FDIC Study at v (cited in note 79) (finding that those who live in low-income zip codes are more likely than others to pay overdraft fees); Protecting Consumers from Abusive Overdraft Fees: The Fairness and Accountability in Receiving Overdraft Coverage Act, Hearing on $S 1799$ before the Committee on Banking, Housing, and Urban Affairs, 111th Cong, 1st Sess 33, 35-36 (2009) (statement of Jean Ann Fox, Director of Financial Services, Consumer Federation of America).

95 Editorial, Debit Card Trap, NY Times A26 (Aug 20, 2009) (citing Moebs Services).

$96 \quad 74$ Fed Reg at 59038.

$97 \quad 74 \mathrm{Fed}$ Reg at 59038.

9874 Fed Reg at 59039.

$99 \quad 74$ Fed Reg at 59044.
} 
Regulators decided to address these concerns using a default based explicitly on research showing that most people stick with the default. Regulators noted that "studies have suggested[] [that] consumers are likely to adhere to the established default rule, that is, the outcome that would apply if the consumer takes no action" and cited studies of the effectiveness of automatic enrollment in increasing participation in retirement savings plans. ${ }^{100}$

Thus, regulators made clear that their goal in promulgating the policy default was not merely to force banks to reveal the existence of overdraft coverage, but to move consumers who would otherwise overdraw their accounts into the default position so as to decrease the incidence of overdraft fees, particularly among those consumers who were otherwise likely to overdraw repeatedly. ${ }^{101}$ On the other hand, regulators also concluded that a small group of consumers might benefit from the "occasional" use of ATM or nonrecurring debit overdraft coverage if they would otherwise "be precluded from completing important transactions" because they lack sufficient funds in their accounts and lack another means of payment.102 These situations are likely to be rare. Transaction records show that on the day they overdraw, most people have a cheaper source of funds available to them in the form of available credit on a credit card or cash in another checking or savings account. ${ }^{103}$ Other consumers might find deferring or forgoing the purchase to be less costly than making the purchase and incurring overdraft fees.

The new rules require banks to place account holders by default into a fee structure that does not charge for overdrafts occasioned by ATM or nonrecurring debit card transactions. ${ }^{104}$ As a result, banks no longer permit ATM and nonrecurring debit transactions to overdraw an account unless the account holder has opted out of the default. Banks can continue their practice, at their discretion and without first obtaining consumer consent, of covering overdrafts occasioned by checks and recurring

\footnotetext{
10074 Fed Reg at 59038 \& n 25.

101 In other words, this was not to be merely an information-forcing penalty default, but a sticky policy default. For a discussion of the distinction between penalty defaults and policy defaults, see note 4 .

10274 Fed Reg at 59039.

103 See Victor Stango and Jonathan Zinman, What Do Consumers Really Pay on Their Checking and Credit Card Accounts? Explicit, Implicit, and Avoidable Costs, 99 Am Econ Rev Papers \& Proc 424, 424-25 (2009).

10412 CFR § 205.17(b); 12 CFR § 205.17(b)(1)-(2) Supp I.
} 
payments and charging a fee. ${ }^{105}$ The Federal Reserve Board explained the regulations' different treatment of different types of transactions as follows: Checks and scheduled recurring payments are not included in the mandated default because consumers expressed a preference for these to be covered, given that these transactions tend to be for necessities such as rent and mortgage payments, and given that when these are not paid a merchant will usually charge the consumer a fee. In contrast, consumers expressed a preference for having ATM and nonrecurring debit transactions declined, given that these tend to be discretionary transactions, and given that when these are declined consumers are not charged a fee. ${ }^{106}$

2. The law governing opting out.

Banks find overdraft coverage lucrative and would prefer consumers be in a position to incur overdraft fees. In designing the new overdraft rule, regulators were mindful of the potential for bank "circumvention or evasion" of the default. ${ }^{107}$ The regulation consists of both a policy default and a surrounding web of altering and framing rules intended to make the default sticky.

The altering rules supporting the new default consist of two parts. First, to opt out a consumer must take an "affirmative" action, ${ }^{108}$ such as speaking to a bank representative in person or by phone, clicking a box on an online banking form, or sending the bank a written request. ${ }^{109}$ The idea is to prevent banks from placing language opting out of the default in routinely unread account disclosures that would lead consumers to passively opt out of the policy default. Affirmative assent to overdraft coverage for ATM and nonrecurring debit transactions must be given once, not for each individual transaction. Second, banks must provide the same account terms, conditions, and features to account holders who stick with the default as they provide to account holders who opt out. ${ }^{110}$ For example, banks cannot condition overdraft coverage for checks and recurring payments on

\footnotetext{
10512 CFR § 205.17(b)(2) Supp I.

10674 Fed Reg at 59040-41.

10774 Fed Reg at 59044.

10812 CFR § 205.17(b)(iii).

10912 CFR § 205.17(b)(4)(i)-(iv) Supp I.

11012 CFR § 205.17(b)(3).
} 
opting out of the ATM and nonrecurring debit transaction default. ${ }^{111}$

The new overdraft rule is also complemented by regulations that attempt to frame the context in which the choice to opt out is presented to consumers. Before consumers can opt out, banks must provide them with a notice that briefly describes the bank's overdraft-coverage program for ATM and nonrecurring debit transactions; the fees imposed for an ATM or nonrecurring debit transaction that overdraws an account; directions for how to consent to overdraft coverage on ATM and nonrecurring debit transactions; and the existence of any alternative plan the bank offers to cover overdrafts, such as a linked savings account or credit card account or line of credit.112 At its option, the bank may also include information about its overdraft practices for checks and recurring payments and the right of the consumer to revoke consent to overdraft coverage for ATM and nonrecurring debit transactions. ${ }^{113}$ To prevent this notice from being buried among the fine print, potentially leading consumers to opt out of the default unintentionally in the course of signing accountopening documents, nothing other than the above may be contained in the legally mandated notice. ${ }^{114}$ However, banks are free to provide other information about their overdraft practices and programs in documents that are separate from this notice. ${ }^{115}$ As an additional safeguard to prevent consumers from unintentionally opting out, banks must provide those who opt out with a confirmation stating that they can opt back into the default. ${ }^{116}$

3. The limited effects of the policy default.

In the abstract, the background conditions under which consumers encounter the overdraft-coverage decision make it seem an apt situation for using a policy default to increase the number of people in the default position. Many people are likely to find mapping their preferences to their overdraft choices challenging, given that it presents a confusing decision environment in which consumers may be uncertain about their preferences.

11112 CFR $\S 205.17(b)(2)$.

11212 CFR § 205.17(d)(1)-(5).

11312 CFR $\S 205.17(d)(6)$.

11412 CFR $§ 205.17$ (d) (stating that the required notice "may not contain any information not specified in or otherwise permitted" by the rule).

11574 Fed Reg at 59047 n 39.

11612 CFR $§ 205.17$ (b)(1)(iv). 
Overdraft options, the fee structures for each of them, the nomenclature used, and the policy default itself are all confusing. Many banks offer at least four overdraft-treatment possibilities: the default overdraft practices that come with checking accounts, overdraft practices that occur if the consumer opts out of the default, overdraft lines of credit, and links from a checking account to a savings account or credit card to cover overdrafts. ${ }^{117}$ Each comes with its own formula for assessing fees, and the fees, formulae, and terminology for each differ at different banks and change over time. ${ }^{118}$ The nomenclature is also confusing. "Standard overdraft practices" is the term used in the Federal Reserve Board's model consent form to describe both what happens when the account holder sticks with the default (at most banks this means coverage for checks and scheduled recurring payments but not ATM or nonrecurring debit transactions) and the fees charged for overdrawing, including by ATM or nonrecurring debit transaction. ${ }^{119}$ Banks call all of these products a variety of different names. For example, "Courtesy Pay," 120 "Account Protector," ${ }_{121}$ "Bounce Protection," "Debit Card

\footnotetext{
117 Some banks offer even more permutations. See, for example, Bob Sullivan, Banks' Hard Sell: Opt In for More Overdraft Fees, The Red Tape Chronicles (NBC News July 30, 2010), online at http://redtape.nbcnews.com/_news/2010/07/30/6345569-banks -hard-sell-opt-in-for-more-overdraft-fees?lite (visited Sept 11, 2013) (describing an overdraft program where the consumer pays $\$ 4.99$ per month in exchange for the ability to overdraw the account by up to $\$ 30$ without incurring an additional fee).

118 For example, some banks charge a flat fee per overdraft, others charge tiered fees depending on the number of overdrafts, some charge a fee for each day the account remains overdrawn or after some specified period has passed and the account has not been brought current, others do not charge for small overdrafts, and so forth. See, for example, 74 Fed Reg at 59033 (discussing fee structures); Cashman, et al, FDIC Study at 13-19 (cited in note 79). Banks use a great variety of different names for these fees. See Susan K. Weinstock, et al, Still Risky: An Update on the Safety and Transparency of Checking Accounts *10 (The PEW Charitable Trusts June 2012), online at http://www.pewtrusts.org/uploadedFiles/wwwpewtrustsorg/Reports/Safe_Checking_in_the _Electronic_Age/Pew_Safe_Checking_Still_Risky.pdf (visited Sept 11, 2013).

119 See Model Consent Form for Overdraft Services, 12 CFR § 205, Appendix A-9. Using "standard overdraft practices" to refer to the fees charged for overdrafts incurred on ATM or nonrecurring debit transactions could lead some consumers to erroneously believe that the default practice is to allow these overdrafts and fees. See Weinstock, et al, Still Risky at *18 (cited in note 118) (explaining that the terminology banks use to describe their overdraft plans can result in consumer confusion).

120 With Courtesy Pay, SMCU Has You Covered (San Mateo Credit Union 2013), online at http://www.smcu.org/accounts/courtesy.php (visited Sept 11, 2013).

121 Standard Overdraft Services: Are You In? (Sovereign Bank 2011), online at http://www.sovereignbank.com/personal/promotions/sovereign-account-protector.asp (visited Sept 11, 2013).

122 Bounce Protection (Central National Bank 2013), online at https://www.centralnational.com/personal/bounceprotection.asp (visited Sept 11, 2013).
} 
Advance," 123 and "Overdraft Privilege"124 are each used by different banks to refer to overdraft coverage on ATM and nonrecurring debit transactions. Even the default is not intuitive, treating ATM and nonrecurring debit transactions differently than checks and scheduled-recurring payments. The opacity of overdraft options presents the potential for a policy default to be very effective.

Overdraft also might be an area where consumer preferences are weak or conflicted. On the one hand, consumers do generally state a preference for the policy default. ${ }^{125}$ Overdrafters themselves say that they dislike the opt-out position, even when they have opted out of the default: Over 75 percent of people who in 2012 reported overdrawing their account in the prior year stated that they would prefer to have nonrecurring debit transactions declined rather than incur a $\$ 35$ overdraft fee..$^{126}$ Over 60 percent of overdrafters said that overdraft coverage hurts people more than it helps them. ${ }^{127}$ On the other hand, most consumers - even frequent overdrafters-do not believe they will overdraw their accounts, except perhaps in the rarest of emergencies. As regulators noted in promulgating the overdraft default, consumers are likely to assume overoptimistically they will not overdraw. ${ }^{128}$ Ninety percent of consumers polled in 2012 who had incurred an overdraft fee in the prior year stated that they overdrew their account by mistake and were surprised by the fee when they became aware of it. ${ }^{129}$ Given that they do not expect to overdraw, many consumers might feel that any decision about the default is inconsequential and therefore hold their preferences about overdraft coverage only weakly. Other

123 TD Debit Card Advance (TD Bank 2013), online at http://www.tdbank.com /tdadvance (visited Sept 11, 2013).

124 Overdraft Privilege (First National Bank 2008), online at http://www.myfnbbank.com/index.php?option=com_content\&task=view\&id=112\&Itemid $=124$ (visited Sept 11, 2013).

125 See notes 105-06 and accompanying text (citing the Federal Reserve Board's finding that consumers preferred to have ATM and nonrecurring debit transactions declined rather than incurring a fee).

126 The PEW Center on the States, Overdraft America: Confusion and Concerns about Bank Practices *5, 9 n 6 (May 2012), online at http://www.pewhealth.org/uploadedFiles /PHG/Content_Level_Pages/Issue_Briefs/SC-IB-Overdraft\%20America.pdf (visited Sept 11, 2013). Even among very frequent overdrafters (those who overdrew more than ten times in the prior year), over half stated a preference that their nonrecurring transactions be declined. Id.

127 Id at $* 3$.

12874 Fed Reg at 59044.

129 The PEW Center on the States, Overdraft America at *4 (cited in note 126). 
consumers, particularly low-income consumers who fear running out of cash, might want overdraft coverage for emergencies, but not for ordinary purchases, such that they are conflicted about their preferences. In theory, these uncertain preferences should tend to make the policy default sticky.

The reality, however, has turned out differently. Although sources report wildly divergent data, the following picture has emerged: Not all banks energetically pursued overdraft revenue after the change in the law, but those that did have managed to achieve high opt-out rates, particularly among consumers with a history of frequent overdrafts and new account holders. By November of 2010, only a few months after the policy default came into effect, one large bank stated that for existing account holders who previously had overdrawn ten or more times per year, four to nine times per year, and fewer than four times per year, the proportions who had opted out of the default were 53 percent, 41 percent, and 21 percent, respectively. ${ }^{130}$ A Consumer Financial Protection Bureau (CFPB) study of a small set of large banks suggests somewhat lower numbers for these banks as of the end of 2010: 45 percent of heavy overdraft users (over 10 overdrafts in the first half of 2010) and 35 percent of moderate users (4 to 10 overdrafts in the first half of 2010) had opted out. ${ }^{131}$ But for the banks with the highest numbers of opt-outs, the CFPB found even higher opt-out rates for heavy overdraft users-66 percent by the end of 2010.132 The CFPB's large-bank data set showed 15 percent of all accounts had opted out by the end of 2010, but by 2012, some of the large banks the CFPB examined were achieving opt-out rates of over 50 percent for all new accounts. ${ }^{133}$ Community banks appear to have pushed overdraft harder; they report opt-out rates of 60 percent across all accounts for those banks that offer overdraft coverage. ${ }^{134}$

Further, the regressive impact of overdraft fees has likely been exacerbated by the new law. Recall that prior to the policy default, frequent overdrafters accounted for over 90 percent of

130 See David Benoit, Customers Opt In for Overdraft Protection, Wall St J C1 (Nov $26,2010)$.

131 Consumer Financial Protection Bureau, CFPB Study of Overdraft Programs: A White Paper of Initial Data Findings 31 figure 5 (June 2013), online at http://files

.consumerfinance.gov/f/201306_cfpb_whitepaper_overdraft-practices.pdf (visited Sept 11, 2013).

132 Id at 33 figure 7.

133 Id at 32 .

134 Id at 29 . 
all overdraft fees. ${ }^{135}$ Since the policy default was imposed, fees per overdraft have risen higher; as noted above, the average fee before the new rule was $\$ 27$, but in 2011 , industry sources reported that the average fee was between $\$ 30$ and $\$ 35 .{ }^{136}$ Total bank revenue from overdraft fees remains high; one source estimates that it decreased less than 15 percent after the policy default went into effect.137 Because frequent overdrafters are more likely to opt out, it appears that these fees are now even more disproportionately borne by this group.

Thus, the primary goals of the policy default-to move consumers who would otherwise overdraw their accounts into the default position so as to decrease the incidence of overdraft fees, particularly among those consumers who were otherwise likely to overdraw repeatedly-do not appear to have been met, certainly not on the scale achieved by the retirement savings automatic enrollment default. Given that the default was developed particularly to help prior frequent overdrafters avoid overdraft fees, it appears to have dramatically failed to achieve this aim.

4. Tools used by banks to make the policy default slippery.

Why is the policy default not stickier, even in the face of altering and framing rules designed to bolster its power and background conditions that in theory seem ideal? If the mechanisms that can make defaults sticky were in fact being triggered now that the default rule has changed, then we might conclude that, contrary to their survey responses, consumers not only prefer overdraft coverage, but prefer it strongly enough to overcome the erstwhile stickiness of the default. This would mean that regulators erred in their judgment when they put the policy default in place. However, evidence on the ground demonstrates that banks, acting largely within the letter of the law, are able to neutralize the mechanisms that lead to stickiness or even redirect those mechanisms to favor opting out. Although the law places

135 See note 93.

136 See Consumer Financial Protection Bureau, Press Release, CFPB Launches Inquiry into Overdraft Practices (Feb 22, 2012), online at http://www.consumerfinance.gov /pressreleases/consumer-financial-protection-bureau-launches-inquiry-into-overdraft -practices (visited Sept 11, 2013). See also note 80 and accompanying text.

137 See Moebs Services, Overdraft Fee Revenue in the US Falls to $\$ 31.6$ Billion in 2011 (Business Wire Mar 15, 2012), online at http://www.businesswire.com/news/home /20120315006272/en/Overdraft-Fee-Revenue-U.S.-Falls-31.6-Billion (visited Sept 11, 2013). Note that this figure reflects all overdraft fees, including those incurred on ATM, debit, check, or electronic transactions. 
some restrictions on the way the default is framed, banks use their substantial discretion to shape the way consumers perceive it. Moreover, due to the greater potential profits to be realized when frequent overdrafters opt out, banks concentrate their efforts on these consumers. ${ }^{138}$

a) Eliminating and inverting transaction barriers.

i) Removing the cost of opting out. Although the transaction costs of opting out can give defaults traction, that is not the case with the overdraft default. Why not? One reason is that banks are able to minimize these costs and, in some cases, to eliminate the difference between the cost of opting out and the cost of sticking with the default.

For existing account holders, banks make opting out as costless as possible. They provide preaddressed stamped cards on which consumers need merely check a box before dropping the card in the mail. They permit consumers to consent by pushing a button on an ATM. ${ }^{139}$ To relieve consumers of even these burdens, banks engage in one-on-one marketing. They station bank employees at ATMs to approach consumers and pitch them on the benefits of opting out. ${ }^{140}$ For consumers with a history of frequent overdrafts, banks call them at home or approach them when they enter a branch to engage in other transactions. ${ }^{141}$

For new customers and for account holders using online banking, transaction costs do not fortify the default because these costs are the same whether the consumer sticks with the default or opts out. Banks structure account-opening forms such

138 See, for example, Sullivan, Banks' Hard Sell (cited in note 117) (quoting a staff attorney at Consumers Union as saying that banks are targeting account holders who have a chronically low balance); Martin and Lieber, Overdraft Open Season, NY Times at B1 (cited in note 90) (reporting that consultants were advising banks to "focus their pitch on the minority of customers who are responsible for the vast majority of overdraft fees").

139 See Laura Northrup, Opt In to Overdraft Protection Right at the ATM (Consumerist July 29, 2011), online at http://consumerist.com/2011/07/29/opt-in-to-overdraftprotection-right-at-the-atm (visited Sept 11, 2013).

140 See Laura Northrup, Chase Now Has Human ATM Greeter Who Helpfully Sells Overdraft Protection (Consumerist July 14, 2010), online at http://consumerist.com/2010 /07/14/chase-installs-atm-greeter-who-sells-debit-card-overdraft-protection (visited Sept 11, 2013) (relaying a bank customer's experience of being confronted by a bank employee when withdrawing money from an ATM).

141 See Karen Weise, Reforms Fail to Halt Bank Revenue on Debit-Card Overdraft Fees (Bloomberg Oct 20, 2011), online at http://www.bloomberg.com/news/2011-10-20 /reforms-fail-to-halt-bank-revenue-on-debit-card-overdaft-fees.html (visited Sept 11, 2013); Ben Popken, Chase Just Goes Ahead and Adds Overdraft Protection to Your Account (Consumerist Sept 16, 2010), online at http://consumerist.com/2010/09/16/chasejust-goes-ahead-and-adds-overdraft-protection-to-your-account (visited Sept 11, 2013). 
that consumers must check precisely the same number of boxes regardless of whether they check the box for sticking with the default or check the box for opting out. Regulators explicitly permit banks to do this, ${ }^{142}$ allowing banks to set up a "mandated choice" scenario ${ }^{143}$ rather than one in which the legal default is accepted through inaction. This may explain why a greater proportion of new customers appear to have opted out of the default than existing account holders. ${ }^{144}$ Banks are able to force some existing account holders into a similar mandated-choice situation. Banks equalize the small cost of opting out to the same small cost consumers must pay to stick with the default by preventing use of online banking until the account holder clears a screen that requires clicking a button accepting or a button rejecting the default. ${ }^{145}$

ii) Making the default position costly. A second reason that costs do not fortify the overdraft policy default is that, despite the altering rule requiring banks to give consumers the same account terms regardless of opt-out status, banks are able to impose costs on those who stick with the default and play on common misperceptions that a failure to opt out will be costly.

When the policy default went into effect, banks bombarded existing account holders with marketing in the postal mail, in email, online, and on ATM screens, attempting to convince them to opt out. ${ }^{146}$ As noted, banks went further for frequent users of overdraft coverage, contacting them by telephone or when they came into branch offices. Declining each offer, even checking a box on an online form stating that the account holder did not

142 See 12 CFR $\S 205.17$ (b)(5) Supp I (“A financial institution may require a consumer, as a necessary step to opening an account, to choose whether or not to opt into the payment of ATM or one-time debit card transactions pursuant to the institution's overdraft service.").

143 See note 13

144 Consumer Financial Protection Bureau, CFPB Study of Overdraft Programs: A White Paper of Initial Data Findings at 31-32 (cited in note 131).

145 See Ben Popken, Banks Luring You into Signing Back Up for High Overdraft Fees (Consumerist June 18, 2010), online at http://consumerist.com/2010/06/18/bankstrying-to-get-you-to-sign-up-for-high-overdraft-fees (visited Sept 11, 2013); Phil Villarreal, When It Comes to Overdraft Opt-In, Chase Won't Take No for an Answer (Consumerist Aug 6, 2010), online at http://consumerist.com/2010/08/06/when-it-comes-tooverdraft-opt-in-chase-wont-take-no-for-an-answer (visited Sept 11, 2013).

146 See, for example, Sullivan, Banks' Hard Sell (cited in note 117) (describing advertising materials and scare tactics banks used to get customers to opt out); Popken, Banks Luring You (cited in note 145); Martin and Lieber, Overdraft Open Season, NY Times at B1 (cited in note 90). 
want to opt out, would not stop the barrage. ${ }^{147}$ Consumers quickly realized that there is an immediate intangible benefit to opting out-the marketing will stop. The calls and emails will cease, the tellers will stop asking, and those who bank online will be able to navigate directly to their personal account without clicking through a computer screen asking whether they would like to opt out first. One survey found that almost half of respondents who reported that they had opted out of the default did so at least in part to stop receiving overdraft marketing. ${ }^{148}$

Banks also flat out violate the prohibition on different account terms by offering a day of "float" to consumers who opt out of the policy default as well as an exemption from the usual requirement that a deposit must clear before it is available. Because check deposits can take up to eleven days to clear, ${ }^{149}$ this can be a substantial benefit. One bank's marketing flyer offers:

Debit Card Overdraft Coverage on your personal account may allow your ATM and everyday debit card transactions to be approved before a deposit is available in your account. . . . [U]se your ATM and debit card and have until the end of the same business day to make a deposit or transfer money to cover your ATM and everyday debit card purchases. ${ }^{150}$

The flyer states that this perk does not apply to those who do not opt out of the default; these consumers are advised that they "may need to make deposits well in advance to ensure [their] ATM and everyday debit card purchases are approved."151

Further, although the law does not allow banks to offer worse terms to those who stick with the default, banks can play on the illusion that a failure to opt out will be costly. Two

147 See Villarreal, When It Comes to Overdraft Opt-In, Chase Won't Take No for an Answer (cited in note 145).

148 Center for Responsible Lending, Banks Collect Overdraft Opt-Ins through Misleading Marketing *3-4 (Apr 2011), online at http://www.responsiblelending.org /overdraft-loans/policy-legislation/regulators/CRL-OD-Survey-Brief-final-2-4-25-11.pdf (visited Sept 11, 2013).

149 Government Accountability Office, Bank Fees: Federal Banking Regulators Could Better Ensure That Consumers Have Required Disclosure Documents prior to Opening Checking or Savings Accounts *21 (Jan 2008), online at http://www.gao.gov/new.items /d08281.pdf (visited Sept 11, 2013).

150 Stay Protected with SharePlus ATM and Debit Card Overdraft Coverage at *1 (SharePlus Federal Bank), online at https://secureforms.c3vault1.com/forms/shareplus /pdf/opt-in-details.pdf (visited Sept 11, 2013).

151 Id. See also Chase Debit at *1 (cited in note 77) (explaining the same day of float perk for consumers who opt out); TD Bank FAQ (cited in note 77) (same). 
misperceptions are common. First, consumers believe that opting out of the default is necessary to avoid bounced checks, even though checks and recurring payments are not affected by the policy default. In one survey, nearly two-thirds of respondents who reported that they had opted out of the default stated that one reason they did so was to avoid bouncing paper checks. ${ }^{152}$ Second, many people believe that opting out is necessary to avoid incurring a fee when a nonrecurring debit card transaction is denied for insufficient funds, even though no such fee exists. Sixty percent of consumers who reported that they had opted out of the default stated that one reason they did so was to avoid this (nonexistent) fee. ${ }^{153}$

Consumer misperception here is driven in part by the complexity of the overdraft policy default and of the fees that apply when different forms of payment are denied. The fact that the policy default applies to ATM and nonrecurring debit transactions but not checks and recurring payments is not intuitive, especially given that some banks call the debit cards they issue "check cards." The fact that some debit card denials do not result in a fee is not obvious, given that when a check or recurring debit transaction is denied, both the merchant and the bank can charge the consumer a fee, and some prepaid debit cards carry declined-transaction fees. ${ }^{154}$ But banks also stoke confusion with overdraft marketing materials that make claims such as: "You can protect yourself from ... fees normally charged to you by merchants for returned items," or "The Bounce Overdraft Program was designed to protect you from the cost ... of having your transactions denied." 155

iii) Exploiting and engendering confusion. Confusion is one mechanism that can make defaults sticky, but it also can lead consumers to inadvertently opt out. Polls suggest that many account holders treated by their banks as having opted out did not

152 Center for Responsible Lending, Consumer Federation of America, and National Consumer Law Center, Comments at 15 (cited in note 78). Consumers who believe that they must opt out to avoid bouncing checks may feel compelled to opt out, given that in most states bouncing a check is a criminal offense and can even result in imprisonment. See Bad Check Laws by States (National Check Fraud Center 2011), online at http://www.ckfraud.org/penalties.html\#criminal (visited Sept 11, 2013).

153 Center for Responsible Lending, Consumer Federation of America, and National Consumer Law Center, Comments at 15 (cited in note 78).

154 See Sandra Block, Prepaid Card Fees Can Hurt: If You Don't Choose Carefully, They Can Squeeze You Dry, USA Today 1B (Jan 18, 2011).

155 Center for Responsible Lending, Banks Collect Overdraft Opt-Ins at *1 (cited in note 148). 
intend to opt out. In a Spring 2012 survey, taken almost two years after the policy default became effective, over half of the consumers who reported having paid an overdraft fee on an ATM or nonrecurring debit transaction in the prior year stated that they did not believe they had opted out of the policy default and into overdraft coverage. ${ }^{156}$ Eight percent did not know whether they had agreed to overdraft coverage.157 Both the existence of substantial numbers of consumers who do not know their opt-out status and the fact that banks treat consumers who do not believe they opted out as having done so indicate that here, ${ }^{158}$ transaction confusion, rather than favoring the default, operates to favor opting out.

The complexity of the policy default and of overdraft generally, explained above, ${ }^{159}$ as well as bank presentation of the optout choice, contribute to this confusion. When consumers are orally asked to opt out, confusion may be especially high. One consumer reported that, after calling her bank about an unrelated matter, the representative

very quickly noted that I didn't have any overdraft protection and that she'd go ahead and do me the favor of adding overdraft protection to my checking account .... She never asked if I wanted the service or even gave me a chance to give her my opinion on the matter. ${ }^{160}$

Bank employees say that their employers require them to sell overdraft coverage using deceptive tactics and that consumers who are convinced to opt out do not understand what has happened.161 These tactics are likely concentrated on frequent overdrafters; at least one bank offered employees a bonus for

\footnotetext{
156 The PEW Center on the States, Overdraft America at *4 (cited in note 126).

157 Id.

158 Although surveys can suffer from biased responses, it is unlikely that consumers would understate their frequency of opting out. Social desirability bias, if present at all, would favor opting out because bank marketing made the argument that consumers ought to opt out, and no constituency that favored sticking with the default was particularly active in the media.

159 See notes 117-24 and accompanying text.

160 Popken, Chase Just Goes Ahead (cited in note 141).

161 See Ben Popken, Get Customers to Sign Up for Overdraft Fees or Get Fired (Consumerist Aug 3, 2010), online at http://consumerist.com/2010/08/03/getting-fired-for-not -tricking-customers-into-overdraft-fees (visited Sept 11, 2013); Ben Popken, Branch Manager Quits rather than Trick Bank Customers into Signing Up for Overdrafts (Consumerist Aug 13, 2010), online at http://consumerist.com/2010/08/13/rather-than-trickbank-customers-into-signing-up-for-overdrafts-branch-manager-quits (visited Sept 11, 2013).
} 
convincing prior users of overdraft coverage to opt out of the default. 162

iv) Making the choice visible. Although another common barrier to opting out of defaults is invisibility, the choice to opt out of the overdraft default is highly visible. The law requires that the choice to opt out be presented in a notice segregated from other account information. ${ }^{163}$ The intent was to prevent banks from switching the default rule in fine-print terms to which consumers blindly consent, but the effect is also to defuse the invisibility mechanism that might otherwise make the default sticky. To consumers who ignore the opt-out notice, banks direct reams of marketing; as noted above, frequent overdrafters may even be called or approached in person. Thus, the policy default garners no traction through the invisibility mechanism.

b) Neutralizing and flipping judgment and decision biases.

i) Repositioning loss aversion and the endowment effect. Loss aversion and the endowment effect can contribute to the power of defaults, but banks use a variety of methods to reposition these biases to induce opting out.

First, banks frame opting out as a gain. In their communications with consumers, banks refer to opting out of the policy default as "opting in" to a bank's "overdraft service."164 Thus, opting out of the default is framed as gaining a service rather than losing an endowed reference position, so that loss aversion and the endowment effect are not triggered to support the policy default.

Instead, banks frame the policy default as a loss. At the request of the banking industry, 165 the regulations allowed banks to obtain consumer consent to opting out prior to the effective date of the new default. ${ }^{166}$ Banks capitalized on this, heavily pitching existing account holders on the right to opt out prior to the operation of the new rule. ${ }^{167}$ Thus, at the time consumers were asked to agree to overdraft coverage, they were being

162 See Ray Birch, Iowa CU's Face-to-Face Pitch Boosts Opt-Ins, 14 Credit Union J 11, 11 (May 31, 2010).

16312 CFR § 205.17(b)(1)(i)-(ii).

164 The regulations use the same language. See, for example, 12 CFR $§ 205.17$ (repeatedly referring to opting out of the default as "opt[ing] in" to overdraft coverage for ATM and nonrecurring debit transactions, and to overdraft coverage as a "service").

165 See 74 Fed Reg at 59047.

16612 CFR § 205.17(c)(1) Supp I.

167 See, for example, Sullivan, Banks' Hard Sell (cited in note 117); Martin and Lieber, Overdraft Open Season, NY Times at B1 (cited in note 90). 
asked to take action to preserve the status quo and avoid losing a currently endowed position. In their marketing, banks explicitly invoked loss aversion to encourage opting out with copy such as "Don't lose your ATM and Debit Card Overdraft Protection" 168 and "STAY PROTECTED with [] ATM and Debit Card Overdraft Coverage," 169 and by framing the overdraft coverage choices as follows:

Figure 1. EXCERPTS FROM BANK OVERDRAFT DEFAULT OPT-OUT FORM $^{170}$

\section{YES \\ KEEP MY ACCOUNT WORKING THE SAME WITH SHAREPLUS} ATM AND DEBIT CARD OVERDRAFT COVERAGE

or

\section{NO \\ CHANGE MY ACCOUNT TO REMOVE SHAREPLUS ATM AND DEBIT CARD OVERDRAFT COVERAGE}

One bank employee frankly explained that nearly all customers could be convinced to opt out by presenting a failure to opt out as a change: "All you have to do to get an almost definite yes is explain that opting in [to overdraft coverage] will keep their account exactly the way it is now. People are scared of change so they'll opt in [to overdraft coverage] to avoid change."171

Even after the new default rule became operative, in somewhat Orwellian fashion, bank marketing has continued to play on loss aversion and the endowment effect. For example, as of this writing, nearly three years after the policy default became effective, one bank's online banking webpage continues to state, "Your ... Checking account has a feature called [] Debit Card Overdraft Coverage .... Don't worry, there's no fee to keep the coverage." 172

168 Don't Lose Your ATM \& Debit Card Overdraft Protection (Lapeer County Bank \& Trust Co 2010), online at http://www.lcbt.com/2747/mirror/debitcardandatmoverdraftprotection.htm (visited Sept 11, 2013).

169 Stay Protected with SharePlus at *1 (cited in note 150).

170 Id (advertising the benefits of overdraft coverage).

171 Sullivan, Banks' Hard Sell (cited in note 117).

172 Chase Debit Card Overdraft Coverage (JP Morgan Chase Bank 2013), online at http://demo.chase.com/presents/preview/pnt/non_pnt/add_overdraft_coverage.html (visited 
More subtly, bank marketing works directly on the query effects $^{173}$ believed to underlie loss aversion, in two ways. First, banks describe the benefits of opting out of the default before presenting consumers with the default itself. Second, in the written or online form banks provide for consumers to opt out, they first present the choice to opt out (phrased as a positivethought-invoking "Yes") and then present the choice to stick with the default (phrased as a negative-thought-invoking "No"). ${ }^{174}$ By channeling the consumer's decision process to consider the benefits of the opt-out position first rather than considering the benefits of the default first, bank marketing flips query effects to encourage consumers to opt out of the overdraft default.

ii) Playing on discounting to favor opting out. When the costs of opting out of a default are immediate and certain, and the gains in the future and speculative, discounting favors sticking with the default. But in the case of overdraft, discounting may encourage opting out.

The benefits of opting out of the overdraft policy default are immediate and appear certain. In addition to stopping the overdraft-marketing barrage described above, there are two benefits consumers may seek when opting out. First, consumers may seek access to overdraft funds immediately. Because account holders can opt out of the policy default at any time, a bank can, at its discretion, provide them with funds as soon as they opt out. ${ }^{175}$ Second, consumers may seek present peace of mind ${ }^{176}$ that they will have access to cash if they encounter an emergency in

Sept 11, 2013) (emphasis added). See also inSight *3 (San Bernardino School Employees Federal Credit Union July 2010), online at http://www.sbsefcu.org/newsletters

/SBInsight_Summer2010.pdf (visited Sept 11, 2013) (“[D]on't worry, there's no fee to keep the coverage available and the fee will apply only if you use it.") (citation omitted).

173 Recall that "query effects" refers to the fact that people tend to generate more answers to the first question they ask themselves than the second, and they routinely ask themselves about the benefits of the reference point before considering the benefits of an alternative. See note 42 and accompanying text.

174 This reverses the order suggested by the Federal Reserve Board's Model Form. For the relevant portion of the form, see text accompanying note 189.

175 See Board of Governors of the Federal Reserve System, Electronic Fund Transfers, 75 Fed Reg 31665, 31667 (2010) (amending 12 CFR $§ 205.17$ ) (noting that a consumer could wait "until the time the [overdraft] service is needed" to opt out of the default).

176 Stay Protected with SharePlus at *1 (cited in note 150) ("Maintain peace of mind with Triple-Protection."); Standard Overdraft Services: Are You In? (cited in note 121) ("Enjoy the peace of mind of knowing your checks, debits, and payments are automatically honored by setting up an Overdraft Protection Plan.”). 
the future. Bank marketing suggests that opting out will provide this, with scripts suggesting, for example, that "No Bounce Advantage" can be a "lifesaver" in case of an "[u]nexpected car repair, maybe when traveling" or for "[m]edical expenses, perhaps a prescription" 177 or "Privilege Pay works like a safety net for your checking account ... so you don't get left stranded at a gas station." 178 Such statements make it appear as if there were no uncertainty about this benefit, even though, as previously noted, banks deny about a third of transactions that would overdraw an account. ${ }^{179}$ Thus, neither the financial nor the psychological benefits of opting out are subject to discounting due to time or uncertainty.

The costs of opting out of this policy default, on the other hand, are uncertain and in the future. Banks frame opting out of the default and into the bank's overdraft program as a "free" perk. ${ }^{180}$ Consumers tend to accept "free" offers—offers with no tangible up-front cost-without pausing to consider true longterm or intangible costs. ${ }^{181}$ Bank marketing may even confuse consumers into believing that not only is opting out of the default "free," but so too is using overdraft coverage once the consumer has opted out. ${ }^{182}$ Oral sales pitches in particular can gloss

177 Bounce Advantage (Peoples Bank 2013) (on file with The University of Chicago Law Review).

178 Privilege Pay (Farmers Insurance Group Federal Credit Union 2013), online at https://www.figfcu.com/print.php?id=610 (visited Sept 11, 2013).

179 See Lieber and Martin, Overspending on Debit Cards, NY Times at A20 (cited in note 77$)$.

180 See, for example, Overdraft Protection (Capital One 2013), online at http://www.capitalone.com/bank/overdraft-protection (visited Sept 11, 2013) ("Opting in is free and easy."); Check Card Overdraft Protection for Your Wescom Checking Account (Wescom Credit Union 2011), online at https://www.wescom.org/accounts/whyoptinover draftprotection.asp (visited Sept 11, 2013) ("Why Opt in to Check Card Overdraft Protection? It's Free.").

181 See Kristina Shampanier, Nina Mazar, and Dan Ariely, Zero as a Special Price: The True Value of Free Products, 26 Mktg Sci 742, 743 (2007). See also David Adam Friedman, Free Offers: A New Look, 38 NM L Rev 49, 69-71 (2008) (discussing deceptiveness of "free" offers); Chris Anderson, Free: The Future of a Radical Price 59 (Hyperion 2009):

A single penny doesn't really mean anything to us economically. So why does it have so much impact? The answer is that it makes us think about the choice. That alone is a disincentive to continue. It's as if our brains were wired to raise a flag every time we're confronted with a price. This is the "is it worth it?" flag. If you charge a price, any price, we are forced to ask ourselves if we really want to open our wallets. But if the price is zero, that flag never goes up and the decision just got easier.

182 See Martha C. White, We Paid Almost $\$ 30$ Billion in Overdraft Fees in 2011 (Time Jan 3, 2012), online at http://business.time.com/2012/01/03/we-paid-almost-30 
over the fees for overdrawing. ${ }^{183}$ Certainly no bank explains that, as noted above, unpaid overdrafts are the primary reason banks involuntarily close and refuse to open checking accounts, meaning that one potential cost of opting out is loss of checkingaccount privileges.

Moreover, overdraft fees are not usually visible or certain at the time when the overdraft occurs. Banks generally do not disclose the fee at the ATM or point of sale, ${ }^{184}$ and it is difficult for consumers to know whether they are overdrawing. Consumers may not know the account balance their bank will assign them at any moment because deposits take varying amounts of time to clear, holds can be placed on account funds, banks reorder transactions within a single day, and account balance statements can be inaccurate. ${ }^{185}$ Consumers only see the actual overdraft fees charged sometime in the future, often not until they receive their monthly statement, and only if they read the statement. ${ }^{186}$ Ninety percent of consumers polled in 2012 who had incurred an overdraft fee in the prior year stated that they

-billion-in-overdraft-fees-in-2011 (visited Sept 11, 2013) (quoting Susan Weinstock of PEW's finding from focus group interviews that "[m]any people think that choosing the bank's 'protection' means that they won't be charged an overdraft fee").

183 See Laura Northrup, TD Bank Sells Overdraft Protection as a "Free" Service (Consumerist Aug 11, 2010), online at http://consumerist.com/2010/08/11/td-bank-sells -overdraft-protection-as-a-free-service (visited Sept 11, 2013) (reporting that a consumer received a phone call from a bank representative who told him that that the bank's "overdraft protection" was "free" and only mentioned fees by saying that the fees for using the service "would stay the same").

184 Cashman, et al, FDIC Study at iii (cited in note 79).

185 See, for example, Government Accountability Office, Bank Fees at *21 (cited in note 149) (explaining that transaction clearing time varies); id at *62 ("Debit card industry representatives explained that the account balance that is used to authorize a debitcard transaction-and which would be displayed to the consumer-may not necessarily reflect the true balance in the consumer's checking account at the time of the transaction."); Cashman, et al, FDIC Study at iv (cited in note 79) (explaining the bank practice of processing withdrawals on a single day from largest to smallest, which maximizes the number of withdrawals that will overdraft the account and overdraft fee revenue). But see Gutierrez v Wells Fargo Bank, NA, 730 F Supp 2d 1080, 1124 (ND Cal 2010) (holding transaction reordering for the purpose of inflating overdraft fees to be a fraudulent practice in violation of California state law).

186 The PEW Center on the States, Overdraft America at *7 (cited in note 126) (finding that reading an account statement was the most common way consumers discovered that they had overdrawn their accounts, with about a quarter learning of the overdraft this way). See also Bob Sullivan, Gotcha Capitalism: How Hidden Fees Rip You Off Every Day-and What You Can Do about It 60 (Ballantine 2007) (quoting a bank employee as stating: "Our focus is to get you to start using the debit cards so you can charge up those [overdraft] fees, because the purchases that you make will not show in your account until many days later"). 
overdrew their account by mistake and were surprised by the fee when they became aware of it. ${ }^{187}$

Consumers do have the right to opt back into the default, but once they have opted out of the default the transaction costs of opting back in are immediate. Because most people-even those who have opted out of the default and even those who have overdrawn frequently in the past-do not expect to overdraw their accounts, ${ }^{188}$ the benefits of opting back in are uncertain and in the future. Discounting therefore can lead to sticking with the opt-out position.

iii) Framing the choice to invoke an action bias. Defaults can sometimes garner adherents through omission bias and regret aversion. But banks are able to neutralize omission bias and even invoke an action bias in the direction of opting out of the overdraft policy default. As explained above, banks place new and online-banking customers in a mandated-choice scenario, forcing them to actively select the default or the opt-out position. Even when banks do not require consumers to make a choice, they typically present the choice in a manner that implies that the consumer must make a choice. In this respect, banks are following the model form developed by regulators, which appears as follows:

Figure 2. EXCERPt From MODEL OVERDRAFt DEFAULT OPTOUT FORM ${ }^{189}$

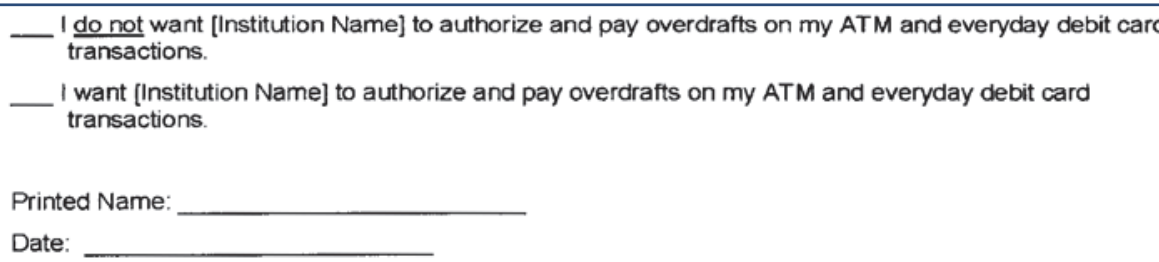

Even if the consumer wants to stick with the default, this presentation implies that action is required on the consumer's part. Without the option to do nothing, the omission bias does not lead consumers to the default position.

187 The PEW Center on the States, Overdraft America at *4 (cited in note 126).

188 See note 129 and accompanying text.

18912 CFR $\S 205$, Appendix A-9 (cited in note 119). See also 12 CFR § 205.17(d)(3) Supp I ("Institutions may, but are not required, to provide a signature line or check box where the consumer can indicate that he or she declines to opt in."). 
While the model form implicitly sends the message that consumers must make an overdraft-coverage choice, bank marketing makes that message explicit. For example, banks instruct account holders that they must take action using language such as: "To keep your account operating smoothly ... [and] [t]o avoid any interruptions in how we service your account, we need to hear from you" 190 and "Urgent notice regarding your ... Debit/ATM Card. Your immediate response is needed! .. . Your signature is required." 191 By framing the choice as one that consumers must make, the message is that consumers are responsible for inaction. Rather than failing to act due to omission bias, consumers may anticipate that if a poor consequence comes to pass, they will regret having failed to take any action.

iv) Reducing procrastination. Procrastination can lead people to stick with the default, but banks work to reduce or eliminate it. As explained above, banks force new customers and existing account holders who wish to use online banking to choose between the default and opt-out positions, so procrastination is not an option. For other existing account holders, particularly those approached in person or by phone and asked to make a choice, procrastination may not appear to be an option. Bank marketing to existing account holders emphasized the effective date of the new default rule as if it were a deadline for opting out, presenting the choice as an urgent one that could not be delayed beyond that point:

190 Center for Responsible Lending, Banks Collect Overdraft Opt-Ins at *1 (cited in note 148) (emphasis omitted).

191 Urgent Notice Regarding Your Public Service Credit Union Debit/ATM Card *1 (Public Service Credit Union 2010), online at https://www.mypscu.com/docs/odpletteronline.pdf (visited Sept 11, 2013). 


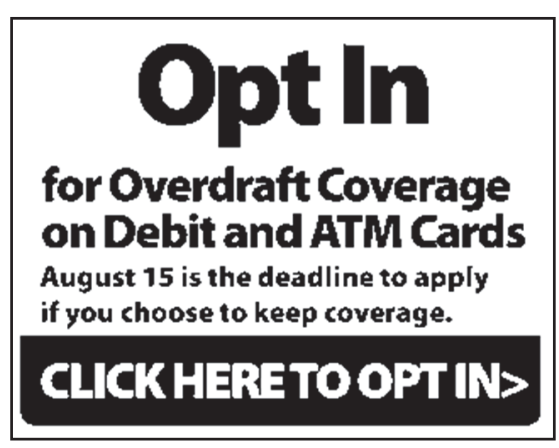

When delay is or appears impermissible, procrastination does not bolster the default.

In addition, some banks may provide consumers with incentives to overcome procrastination. Firms that offer overdraftmarketing services have advised banks to provide gifts or cash offers to prior frequent overdrafters to encourage them to respond to the bank's request that they opt out of the default (regardless of whether that response is to check the box opting out or the box keeping the default). ${ }^{193}$ In addition to overcoming procrastination, such incentives to make an active decision likely increase the visibility of the choice to opt out and work against the omission bias.

c) Shaping preferences. In the context of overdraft, banks have undermined the implicit advice and experience mechanisms through which defaults can sometimes gain adherents. Bank presentation of the policy default, following the model form displayed above, does not reveal which is the default position, consenting to overdraft coverage or not consenting. Some banks further obscure that the default is a default. One bank's opt-out form claims that a decision to opt out is "effective

192 Jim Bruene, Debit Card Overdraft Protection: 2 Steps Forward, 1.9 Back (Netbanker July 13, 2010), online at http://www.netbanker.com/2010/07/debit_card_overdraft _protection_2_steps_forward_19_back.html (visited Sept 11, 2013) (copied from the thenhomepage of Horizons North Credit Union).

193 See Center for Responsible Lending, et al, Comments on Regulations DD and EOverdraft *9 (Consumer Federation of America Mar 30, 2010), online at http://www .consumerfed.org/elements/www.consumerfed.org/file/FRB_Overdraft_Comment_3_30 _10.pdf (visited Sept 11, 2013). 
immediately," but for those who choose to stick with the default "your account(s) will reflect your decision on or before the second business day after your decision has been submitted." 194 The same bank's flyer states "if . . . you don't want your everyday debit card transactions authorized when you don't have sufficient funds in your account, your banker can remove this service from your account." 195 By stating that overdraft coverage needs to be removed and that a decision to decline it is not effective for two days, the bank creates the misimpression that having overdraft coverage is the default. The effect is to rob the policy default of any implicit advice it might otherwise have carried, and to subtly convey advice to opt out.

In addition, banks explicitly advise consumers to opt out. For example, several banks are using advertising copy that tells their customers: "The majority of our members prefer having this service." ${ }^{196}$ Particularly for consumers who are confused by overdraft options, following the herd may seem like sound advice.

Finally, as explained above, existing account holders were pressed to opt out of the policy default before it came into effect and thus before they experienced it. New customers must make a decision at account opening, possibly before they have experienced it. Without living with the default and perhaps discovering that purchases can be foregone or cheaper sources of shortterm credit are available, consumers are not induced to choose the default due to experience.

None of this analysis tells us whether those consumers who opt out of the overdraft policy default are better off with overdraft coverage or would be better off without it. People often make the right decisions for the "wrong" reasons. Someone who is motivated by loss aversion to opt out, for example, might be better off even though she did not engage in a rational weighing

194 Screenshot on file with author. Relevant excerpt from screenshot also available at Oscar Valles, Chase Debit Card Overdraft Coverage and Chase Overdraft Protection Program (Oscar Valles July 17, 2010), online at http://oscarvalles.wordpress.com/2010 /07/17/chase-debit-card-overdraft-coverage-and-chase-overdraft-protection-program (visited Sept 11, 2013) (describing one customer's experience of still being charged overdraft fees after opting out, and showing an image of the relevant text).

195 Center for Responsible Lending, et al, Comments on Regulations DD and EOverdraft at Appendix (cited in note 193). See also Chase Debit at*1 (cited in note 77).

196 Important Information Affecting Your Overdraft Services (ABCO Federal Credit Union 2013), online at http://www.goabco.org/rege.cfm (visited Sept 11, 2013); Important Information Affecting Your Checking Account (Athol Credit Union 2009), online at http://www.atholcreditunion.com/home/personal/odp (visited Sept 11, 2013). 
process first, just as someone who sticks with the default due to procrastination might be better off, and both will have been spared the time and energy of determining the rationally "correct" decision. To judge whether people are making welfareenhancing choices requires more than knowing how they arrived at their choices.

What this analysis does tell us is that, once regulators have decided that people would be better off in a particular position, making that position the default will not necessarily achieve this end. If the regulators who put the overdraft policy default in place are correct that very few consumers benefit from debit and ATM transactions that overdraw their accounts and that past frequent overdrafters in particular would be better off without overdraft coverage for ATM and debit transactions, then the policy default has not been particularly successful in increasing consumer welfare.

\section{B. Boundary Conditions on Using Policy Defaults}

How generalizable is the overdraft case? Are lessons from the overdraft experience transferable to other contexts? Four factors appear to contribute to the slipperiness of the overdraft default: (1) one party opposes the default strongly enough to incur costs trying to make the default slippery, (2) that opposed party has access to the party the default aims to aid (typically a consumer) when the consumer is in a position to opt out, (3) the consumer finds the decision confusing, and (4) the consumer lacks clear preexisting preferences about the decision. Ironically, the last two factors also contribute to the stickiness of defaults. When consumers do not understand their options well and have weak or conflicted preferences, defaults are more likely to influence outcomes. But firm actions to manipulate altering rules and shape the frame in which the consumer perceives the default are likely to have more influence on consumers in these conditions as well.

1. A sufficiently opposed party.

The key difference between the retirement savings planparticipation default and the overdraft default is the presence of an opposed party. In the retirement savings case, no party with access to the employee opposes the default. Retirement savings 
plan service providers generally benefit when more employees stick with the participation default ${ }^{197}$ and employers have some incentives to encourage participation. ${ }^{198}$ Banks, on the other hand, lose overdraft revenue when consumers, and frequent overdrafters in particular, opt out. They therefore have a strong profit motive to induce account holders to opt out. Further, the revenue banks could lose is apparently large enough, and thus their opposition to the policy default strong enough, to compensate for the cost of efforts to steer consumers out of the default.

A number of policy default contexts look like the retirementsavings context in this respect. For example, when Washington State citizens register their cars, by default a $\$ 5$ contribution to the state's parks is added, meaning the citizen must opt out if she does not want to make the contribution. ${ }^{199}$ No party involved has any interest in inducing citizens to opt out, so this default is likely to be sticky. A similar situation is presented by the DoddFrank Act's ${ }^{200}$ new property-taxes and hazard-insuranceescrowing default rule for certain high-cost mortgages. ${ }^{201}$ Escrowing is legally required for the first year of the loan, after which it becomes a default from which borrowers can opt out.202 In the past, lenders offered non-escrowing loans to lower the apparent monthly cost of the mortgage as part of the loan sales pitch. ${ }^{203}$ Because no party has an interest in making mortgage costs appear artificially low a year into the loan, the new escrowing default is likely to be sticky.

Other policy default contexts are closer to the overdraft default on this score. The following are three examples where

197 Plan service-provider compensation often increases when more employees participate or when more assets are under their management. See Deloitte Consulting LLP, Inside the Structure of Defined Contribution/401(k) Plan Fees: A Study Assessing the Mechanics of the 'All-In' Fee *5, 30 (Investment Company Institute Nov 2011), online at http://www.ici.org/pdf/rpt_11_dc_401k_fee_study.pdf (visited Sept 11, 2013).

198 Higher participation levels benefit employers because participation increases employee productivity and retention, particularly for those employees whom employers value more. See William E. Even and David A. Macpherson, Benefits and Productivity, in Olivia S. Mitchell, et al, eds, Benefits for the Workplace of the Future 43, 48-49 (Pennsylvania 2003).

199 Wash Rev Code $\S$ 46.16A.090(3).

200 Dodd-Frank Wall Street Reform and Consumer Protection Act (Dodd-Frank Act), Pub L No 111-203, 124 Stat 1376 (2010).

201 Dodd-Frank Act $\S 1461,124$ Stat at 2178.

20212 CFR § 226.35(b)(3)(iii).

203 See Jack M. Guttentag, Should Escrows Be Mandatory? (The Mortgage Professor July 2, 2007), online at http://www.mtgprofessor.com/A\%20-\%20Escrows/should_escrows _be_mandatory.htm (visited Sept 11, 2013). 
defaults face highly motivated opposed parties: First, almost all states by default allow shareholders to collect damages from the firm's directors if those directors fail to perform their duties with care. ${ }^{204}$ To minimize their potential liability, directors have successfully inserted a provision waiving shareholders' default rights to collect damages into 99 of the top Fortune 100 companies' articles of incorporation. ${ }^{205}$ Second, in the privacy arena, one of the more prominent policy defaults ${ }^{206}$ that has been proposed is a do-not-track default such that web user online activity could not be tracked without affirmative user consent. ${ }^{207} \mathrm{Be}$ cause many websites use tracking data or sell it (or sell access to third parties that can track users through the website), typically for targeted-marketing purposes, ${ }^{208}$ these websites can be

204 See Tamar Frankel, What Default Rules Teach Us about Corporations; What Understanding Corporations Teaches Us about Default Rules, 33 Fla St U L Rev 697, 699700 (2006).

205 See J. Robert Brown Jr and Sandeep Gopalan, Opting Only In: Contractarians, Waiver of Liability Provisions, and the Race to the Bottom, 42 Ind L Rev 285, 309-10 (2009).

206 Many other privacy-protective policy defaults have been proposed. For example, a bill pending in the California legislature would require social networking sites to default consumers into "do not share" privacy settings, such that consumers would have to opt out to give others access to their postings. Social Networking Privacy Act, SB 242, 2011-2012 Cal State Legis (2011) (refused as of June 2, 2011). A bill pending in Congress would require companies that collect data about consumers online to exclude sensitive information like medical condition or religious affiliation by default, such that consumers would need to opt out for this information to be collected. Commercial Privacy Bill of Rights Act of 2011, S 799, 112th Cong, 1st Sess (Apr 12, 2011).

207 In the matter of Google/DoubleClick, FTC File No 071-0170, *20 (Dec 20, 2007) (concurring statement of Jon Leibowitz) ("Perhaps the best solution for consumers is a change in the widespread opt-out default for ... tracking mechanisms to an opt-in default to allow consumers affirmatively to consent."). However, the Commission's most recent report in this area is unclear as to whether it believes do-not-track should be the default, track-me should be the default from which consumers could then opt out, or consumers should be required to make a choice between do-not-track and track-me. Compare Protecting Consumer Privacy in an Era of Rapid Change: Recommendations for Businesses and Policymakers *1 (Federal Trade Commission Mar 2012), online at http://www.ftc.gov/os/2012/03/120326privacyreport.pdf (visited Sept 11, 2013) (suggesting that privacy should be "the 'default setting' for commercial data practices"), with id at 52-55 (suggesting that consumers be given the "choice" not to be tracked for certain purposes).

Further, what a do-not-track policy default would mean is unclear. Open questions include whether it would apply to websites users visit or only to third parties that use those websites to track users, whether it would prohibit collection of data for all purposes or for only specific purposes, and whether it would permit collection where the data is anonymized. See generally id (suggesting a regulatory framework for internet privacy). For illustrative purposes, this Article uses a simplified construct of a do-not-track policy default: no tracking by any party for any purpose without explicit user consent.

208 See, for example, James Temple, Privacy Worries Persist on Tracking, San Francisco Chronicle D1 (Mar 7, 2012) ("Targeting ads based on search queries, sites visited, 
expected to strive to make such defaults slippery. Third, the insurance exchanges that will soon be established under the Affordable Care Act ${ }^{209}$ may either allow individuals who apply to an exchange to be enrolled in a default plan or offer these applicants a small set of default plans to choose from. ${ }^{210}$ Competing health insurance plan sellers will have an interest in seeing that individuals opt out of the default plans and into their competing plans.

A contrasting example is the Credit Card Accountability Responsibility and Disclosure Act's ${ }^{211}$ (Credit CARD Act) new policy default that, much like the overdraft default, requires card issuers to obtain express consumer consent before charging over-thelimit fees.212 Issuers oppose the default, but apparently not strongly enough to spend much effort steering consumers out of the default. This is because alongside the default are substantive restrictions that, as a practical matter, cap over-the-limit fees at $\$ 35$ per account holder per month. ${ }^{213}$ Most issuers have determined that the restricted fees they could earn if consumers

stories read and social connections forms the core of the multimillion-dollar business models of many online companies, including Google, Yahoo and Facebook.").

209 Affordable Care Act $\S 1311$ (b)(1), 124 Stat at 173. The other policy default under the Affordable Care Act is a health care plan automatic enrollment default for new fulltime hires of large employers. Affordable Care Act $\S 1511,124$ Stat at 252. However, until regulations governing the characteristics of these default plans are released that make clear the costs of these plans to employers as compared to the costs employers would incur if employees opt into another plan offered by the employer or out of employer-sponsored health insurance entirely, it is unclear whether employers will oppose this default.

210 See, for example, Brendan S. Maher, Some Thoughts on Health Care Exchanges: Choice, Defaults, and the Unconnected, 44 Conn L Rev 1099, 1112 (2012) ("A regulator can choose a default such that a person can 'one-click' for default coverage of a specified quality and price, and make the default option a prominent option of the exchange website."); Choice Architecture: Design Decisions That Affect Consumers' Health Plan Choices *10-12 (Kleimann Communication Group and Consumers Union July 9, 2012), online at http://consumersunion.org/wp-content/uploads/2013/02/Choice_Architecture_Report.pdf (visited Sept 11, 2013) (describing how current computerized health plan chooser tools similar to those that the exchanges will use usually provide consumers with a short default list of plans on the first computer screen, selected using metrics chosen by the exchange and a few pieces of information about the consumer).

211 Credit Card Accountability Responsibility and Disclosure Act of 2009 (Credit CARD Act), Pub L No 111-24, 123 Stat 1734.

21212 CFR § 226.56(b).

213 See 12 CFR $\S 226.52(b)(1)$ (stating that the fee must reflect actual costs or fall within a safe harbor dollar figure of $\$ 25$, or in some cases $\$ 35$ ); 12 CFR $\S 226.52(b)(2)(\mathrm{i})$ (prohibiting the fee from being larger than the amount by which the credit limit was exceeded); 12 CFR $\S 226.56(j)(1)(i)$ (limiting card issuers such that no more than one fee can be charged each billing cycle). 
opted out are not worth the cost of engaging in maneuvers designed to make the default slippery. ${ }^{214}$

2. Access to consumers by that opposed party.

Another element that is key to the slipperiness of the overdraft policy default is one shared by the retirement savings participation default-access to consumers when they are choosing whether to opt out or stick with the default. In addition to the raw ability to communicate with employees and account holders at home-and, in the case of employers and plan service providers, at the workplace-employers and banks have relationships with their employees and their customers that make it likely that the latter will pay attention to the communication. An account holder who sees that it is her own bank that is sending the communication is likely to open and at least skim the email or postal mail, scan the pop-up screen, answer the telephone, or listen to the bank representative when approached at the branch. Because the consumer can opt out by dropping a postcard back in the mail, clicking a link on the email or pop-up screen, or saying "yes" on the telephone or in the branch, the bank has an opportunity to frame the consumer's thinking about the default at a time when she can opt out. Employers and plan service providers can likewise use their access to encourage employees to stick with the participation defaults at the time the employee is presented with retirement-savings choices.

Opposing parties do not always have such access to the parties that policy defaults aim to assist. For example, certain religious organizations might oppose a sex education class policy default for schoolchildren ${ }^{215}$ or a do-not-resuscitate default for the terminally ill. ${ }^{216}$ But these opposed parties will only have access

214 See, for example, Maria Aspan, Law Hits Home as Cards Opt Out of Overlimit Fees, 174 Am Banker 1 (Aug 10, 2009) (explaining that card issuers are eliminating overthe-limit fees because the prospective returns are no longer worth the costs to issuers).

215 See US Centers for Disease Control and Prevention, New York: Some Catholic Officials Urge Parents to Opt Out of Mandated Sex Education (The Body Aug 11, 2011), online at http://www.thebody.com/content/63488/new-york-some-catholic-officials-urge -parents-to-o.html (visited Sept 11, 2013).

216 See Erik DeLue, Default Medicine: What We Need for EOL Care (Today's Hospitalist Feb 2011), online at http://todayshospitalist.com/index.php?b=articles_read $\& c n t=1172$ (visited Sept 11, 2013) (advocating making do-not-resuscitate the default for the terminally ill); Daniel J. Brauner, Reconsidering Default Medicine, 58 J Am Geriatrics Socy 599, 600 (2010) (suggesting changing the default from life-sustaining feeding to comfort feeding for the terminally ill). 
to their members and are unlikely to influence the opt-out decisions of others.

Other situations are likely to present opposing parties with significant opportunities to circumvent the altering rules intended to make policy defaults sticky and to shape the frame in which the other party perceives the policy default. Corporate directors draft amendments to articles of incorporation and control when amendments come up for a shareholder vote, and so can frame the context in which shareholders decide whether to opt out of their default right to collect damages from directors who violate the duty of care. ${ }^{217}$ Websites could take the liberty of framing a do-not-track default each time users who had not opted out attempted to access the websites. ${ }^{218}$

Even without a formal link, opposing firms can sometimes obtain access to the other party during her opt-out decision process. In the case of default health-insurance plans offered through exchanges, if a competing provider has a means of contacting consumers and knows when they are selecting a plan (for example, by tracking who has accessed the exchange's website), the competitor might bombard consumers with marketing at that point and perhaps offer them an inducement to opt out. A scenario with some similarities occurred when Sweden started requiring citizens to place a portion of earnings into a retirement savings account, which was invested in a lowcost default fund if the citizen did not affirmatively select

\footnotetext{
217 See Brown and Gopalan, 42 Ind L Rev at 312-13 (cited in note 205).

218 It might appear that the user's browser stands between the user and websites, given that one way a user could opt out of a do-not-track default might be by changing a setting on her browser, which would send a signal to websites conveying the user's status as having opted out. See Do Not Track (Electronic Frontier Foundation), online at https://www.eff.org/issues/do-not-track (visited Sept 11, 2013). However, browsers cannot prevent tracking. When Microsoft announced that the next version of its browser would set do-not-track as the default, firms that track web users promptly announced that they would not follow the instruction. See Ryan Singel, IE 10's "Do Not Track" Default Dies Quick Death: Outrage from Advertisers Appears to Have Hobbled Microsoft's Renegade Plan (Ars Technica June 7, 2012), online at http://arstechnica.com/information -technology/2012/06/ie-10s-do-not-track-default-dies-quick-death (visited Sept 11, 2013).

Even if browsers could prevent tracking, websites could lobby users to opt out of the default with respect to their website, provide perks to users who opt out, or even set opting out as a condition of accessing the site. See Edward J. Janger and Paul M. Schwartz, The Gramm-Leach-Bliley Act, Information Privacy, and the Limits of Default Rules, 86 Minn L Rev 1219, 1244 (2002) (expressing skepticism that a privacy-protective default would be sticky because firms would give consumers incentives to opt out or would condition the receipt of services on opting out).
} 
another fund. ${ }^{219}$ Firms were not involved in the opt-out process; the government administered the program. However, firms engaged in a massive marketing campaign to convince citizens to opt out of the default and invest instead in the firms' funds. ${ }^{220}$ Those firms with the most to gain-those offering the highestpriced funds-were very successful in convincing people to opt out of the default and into high-priced funds. ${ }^{221}$

\section{Confusing decision environment.}

Another way in which the retirement savings and overdraft situations are similar is that consumers find their options confusing. Employees understand their employers' retirement plans and investment options no better than checking account holders understand their overdraft options. ${ }^{222}$ Ironically, consumer confusion facilitates both mechanisms that make defaults sticky and the manipulation of those mechanisms that make defaults slippery. When consumers understand their options-whether due to particular sophistication with the context at hand, help from an expert intermediary, ${ }^{223}$ or because the context is simple even for those with limited experience and knowledge- - both defaults and attempts by firms to manipulate consumers' opt-out

219 See Henrik Cronqvist and Richard H. Thaler, Design Choices in Privatized Social-Security Systems: Learning from the Swedish Experience, 94 Am Econ Rev Papers \& Proc 424, 424 (2004).

220 Further, the government advised citizens to make their own choices rather than relying on the default fund, see id, thereby removing any implicit advice that might otherwise have favored the default. Citizens were therefore particularly receptive to marketing aimed at convincing them to opt out.

221 See Henrik Cronqvist, Advertising and Portfolio Choice *3, 23-26 (unpublished dissertation, The University of Chicago Graduate School of Business, 2005), online at http://web.econ.unito.it/cerp/Appuntamenti/Conferenza\%202005/paper\%20e

\%20presentazioni/Cronqvist05.pdf (visited Sept 11, 2013).

222 See, for example, Alan L. Gustman, Thomas L. Steinmeier, and Nahid Tabatabai, Do Workers Know about Their Pension Plan Type? Comparing Workers' and Employers' Pension Information, in Annamaria Lusardi, ed, Overcoming the Saving Slump: How to Increase the Effectiveness of Financial Education and Savings Programs 47, 59, 61 table 2.4 (Chicago 2008) (presenting evidence from 2004 that nearly 40 percent of employees could not accurately identify whether they had a defined benefit or defined contribution plan); Shlomo Benartzi and Richard H. Thaler, Naive Diversification Strategies in Defined Contribution Saving Plans, 91 Am Econ Rev 79, 96 (2001) (showing that employees understand the investment options in their defined contribution plans so poorly that they often divide their money evenly among the options rather than attempting to construct a balanced portfolio).

223 See, for example, Bernard S. Black, Is Corporate Law Trivial?: A Political and Economic Analysis, 84 Nw U L Rev 542, 557 (1990) (arguing that corporate law defaults are so slippery as to be trivial because even small corporations consult attorneysexperts who understand the default and alternatives to it well). 
decisions will have weak effects. Bank personnel, for example, are likely to have overdraft coverage on their personal accounts if and only if they want the actual product offered, no matter the default or marketing designed to push consumers out of the default. On the other hand, when consumers find their options opaque, the default might act as a decision-impasse breaker, but advice conveyed through marketing might perform the same role.

Many consumers poorly understand their options in many decision contexts, so this is not unique to the overdraft and retirement settings. In the privacy arena, consumers are largely oblivious to the firm-set defaults that currently exist. Many do not know that websites currently track their internet use.224 Among web users who know they are being tracked, what information is collected, who has access to it once it is collected, and how it can be used are all frequently mysterious.225 Two-thirds are unaware of options they have to limit how much information is collected about them, ${ }^{226}$ and even sophisticated users can find it impossible to use those options effectively. ${ }^{227}$ Putting a do-nottrack policy default in place, even if supported by framing rules requiring that consumers be given information explaining the default, is unlikely to clarify matters much. The variety of data that can be collected through tracking and the ways that data

224 See Joseph Turow, et al, Americans Reject Tailored Advertising and Three Activities That Enable It *21 table 9 (SSRN Working Paper Series, Sept 29, 2009), online at http://ssrn.com/abstract=1478214 (visited Sept 11, 2013) (finding that only 48 percent of users know that their internet use currently can be tracked across multiple websites without their consent); Opinion Surveys: What Consumers Have to Say about Information Privacy; Hearing before the Subcommittee on Commerce, Trade and Consumer Protection of the Committee on Energy and Commerce, 107th Cong, 1st Sess 7-11 (2001) (statement of Lee Rainie, Director, Pew Internet \& American Life Project) ("[T]he majority of Internet users ... feel they are anonymous online unless they take affirmative steps to disclose information about themselves.").

225 See, for example, Blase Ur, et al, Smart, Useful, Scary, Creepy: Perceptions of Online Behavioral Advertising *4-5 (Carnegie Mellon University CyLab Apr, 2 2012), online at http://www.cylab.cmu.edu/files/pdfs/tech_reports/CMUCyLab12007.pdf (visited Sept 11, 2013); Aleecia M. McDonald and Lorrie Faith Cranor, An Empirical Study of How People Perceive Online Behavioral Advertising *4-8 (Carnegie Mellon University CyLab Nov 10, 2009), online at http://www.cylab.cmu.edu/files/pdfs/tech_reports /CMUCyLab09015.pdf (visited Sept 11, 2013). Most consumers falsely believe that the law restricts website use of consumer information significantly. See Turow, et al, Americans Reject Tailored Advertising at *21 table 9 (cited in note 224).

226 See Kristen Purcell, Joanna Brenner, and Lee Rainie, Search Engine Use 2012 *3 (Pew Research Center's Internet \& American Life Project Mar 9, 2012), online at http://pewinternet.org/ /media/Files/Reports/2012/PIP_Search_Engine_Use_2012.pdf (visited Sept 11, 2013).

227 See Leon, et al, Why Johnny Can't Opt Out at *4 (cited in note 34). 
can be used and disseminated are too complex. One set of researchers who found that simplifying the language and formatting of privacy policies barely improved consumer comprehension explained it this way: "[E]ven the most readable policies are too difficult for most people to understand and even the best policies are confusing." 228 In the face of consumer confusion, parties that oppose a do-not-track default would likely be successful in neutralizing or flipping the mechanisms that otherwise could make the default stick.

In the health insurance arena, confusion is just as high, suggesting that unopposed defaults will be sticky, but defaults opposed by parties with access to consumers will be slippery. Health plans can vary along many dimensions, including the scope of covered services, participating providers, quality measures, and pricing schemes (which include deductibles, copays, and out-of-pocket limits). ${ }^{229}$ Even limiting consideration to the single dimension of pricing would cause consumers to have great difficulty determining the best plan for their needs. ${ }^{230}$ It is thus unsurprising that consumers who use computerized tools for choosing a health plan usually select a plan from among a short default list of plans on the first computer screen. ${ }^{231}$ When the Affordable Care Act's exchanges are established, efforts by opposing insurers to steer consumers to opt out might also be powerful.

\section{Preference uncertainty.}

The fourth reason that efforts by banks to move consumers out of the overdraft default have been successful is that consumer preferences are weak and/or conflicted. As with confusion, preference uncertainty facilitates the operation of mechanisms that can increase the power of defaults, but also can increase the power of framing that leads consumers to opt out. Again, the overdraft and retirement savings decision contexts share this feature. Employees know they want to save something for retirement, but because they are conflicted or uncertain about how much to save or how to invest it, some do not participate in defined contribution plans unless, through automatic enrollment, a

228 Aleecia M. McDonald, et al, A Comparative Study of Online Privacy Policies and Formats, 5672 Lecture Notes in Comp Sci 37, 50 (2009).

229 See Choice Architecture at *4, 20-25 (cited in note 210).

230 See id at *20.

231 See id at *15. 
default contribution rate and investment fund are selected for them. ${ }^{232}$

Both defaults and efforts to move consumers out of defaults are less powerful when consumers have clear, strong preferences. For example, by the time they complete their application for a marriage license, most people will have decided what last name they would like to have and so will not be swayed by the default. ${ }^{233}$ In one experiment, low-income tax filers who had part of their tax refund placed in a savings vehicle by default were no more likely to save than those who received all of their refund immediately with an option to affirmatively choose to save. ${ }^{234}$ The likely explanation for the powerlessness of the default is that, at the time of tax filing, most low-income filers have preexisting plans about how they will spend their refunds, meaning that their preference to spend rather than save is strong enough not to be affected by the default. ${ }^{235}$ Similarly, internet users with strong privacy preferences, when not stymied by the technical challenge, are likely to end up in the position they desire regardless of whether the default is track-me or do-not-track.

However, domains in which many consumers lack clear, strong preferences are likely to be plentiful. Under the current track-me default, users simultaneously say they highly value privacy and take virtually no steps to protect it-the so-called "privacy paradox." This is not only because protecting privacy is technically difficult but also because users' own preferences are conflicted. ${ }^{236}$ For web users who are not privacy advocates, trading

\footnotetext{
232 See James J. Choi, David Laibson, and Brigitte C. Madrian, Reducing the Complexity Costs of 401(k) Participation through Quick Enrollment, in David A. Wise, ed, Developments in the Economics of Aging 57, 58 (Chicago 2009) (finding that, even without the participation default, giving employees a way to enroll at a default contribution rate with a default investment allocation increased participation rates dramatically).

233 See Emens, 74 U Chi L Rev at 769 (cited in note 23) (noting that people have strong feelings about whether to keep or change their names); id at 812-16 (explaining that the social norm that a woman should take her husband's last name is much more powerful than the legal default rule in marital names, which in most states is to retain one's existing name).

234 Erin Todd Bronchetti, et al, When a Nudge Isn't Enough: Defaults and Saving among Low-Income Tax Filers *28-29 (NBER Working Paper 16887, Mar 2011), online at http://www.nber.org/papers/w16887 (visited Sept 11, 2013).

235 Id.

236 See, for example, Patricia A. Norberg, Daniel R. Horne, and David A. Horne, The Privacy Paradox: Personal Information Disclosure Intentions versus Behaviors, $41 \mathrm{~J}$ Consumer Affairs 100, 118 (2007) (finding that people say they are willing to provide less personal information than they actually provide due partly to different perceptions of risk and trust when asked about intentions as compared to actual disclosure settings);
} 
off the benefits that websites are likely to give them for opting out of a do-not-track default versus the privacy benefits of sticking with the default is likely to be challenging even if they understand what information is collected and how it is used. For health insurance, consumers want both low prices and comprehensive coverage and find tradeoffs between the two difficult to make. ${ }^{237}$ In addition, people do not know what their health needs will be in the next year, meaning it is impossible to know which plan will cover their needs at the lowest price. Both health and privacy are "protected values," such that people are averse to making tradeoffs against them and will resort to decision strategies that avoid the subjective experience of such tradeoffs. ${ }^{238}$ Given uncertain preferences in both domains, consumer decisions can be heavily influenced by framing. Therefore, websites are likely to successfully defuse the power of a do-not-track default, and if they can obtain access to consumers choosing a health plan, competing health insurers are likely to successfully defuse the power of health-plan defaults.

In sum, the conditions that make the overdraft default slippery are not unique. Policy defaults are likely to be slippery when consumers find the decision context confusing and/or are uncertain about their preferences and firms have the means and the motivation to induce consumers to opt out. ${ }^{239}$

James P. Nehf, Shopping for Privacy on the Internet, 41 J Consumer Affairs 351, 359 (2007).

237 See Arthur Schram and Joep Sonnemans, How Individuals Choose Health Insurance: An Experimental Analysis, 55 Eur Econ Rev 799, 804 (2011) (experimentally finding that people select health insurance policies by satisficing on one attribute at a time, rather than by making tradeoffs).

238 See Jonathan Baron and Mark Spranca, Protected Values, 70 Org Beh \& Human Dec Processes 1, 5-6 (1997).

239 This does not mean that the boundary conditions on policy defaults identified here are an exhaustive list. For example, where consumers perceive the default to have been selected by a party with opposing interests, they often opt out. See Christina L. Brown and Aradhna Krishna, The Skeptical Shopper: A Metacognitive Account for the Effects of Default Options on Choice, 31 J Consumer Rsrch 529, 537 (2004). Thus, if consumers believe policymakers have set a policy default without consumers' best interests in mind, they might reject it on that basis. 


\section{CAN the LaW Make Defaults Sticky . . But Not Too STICKY?}

\section{A. Policy Defaults Must Be Defaults}

Can policymakers ever use defaults as a policy tool to benefit consumers who find the situation confusing and their own preferences uncertain when firms have a strong incentive to induce consumers to opt out and those same firms have access to consumers at a time when those consumers can opt out? Can policy defaults be complemented with regulation that would overcome the boundary conditions identified above? As a rudimentary step, policymakers must require that the policy default truly be a default. Rather than allowing firms to impose a mandated choice on consumers, the law must demand that firms format the decision-making environment so that inertia is an option and it leads to sticking with the default. To complement this altering rule, a framing rule is needed: firms must be prohibited from creating the misimpression that the policy default is not a default. These steps would ensure that at least the minimal transaction cost of checking a box or saying "yes" to a firm representative favors the policy default. They would allow omission bias and procrastination mechanisms to bolster the default. And they would increase the likelihood that consumers will understand which position has been selected as the default, perhaps conveying some implicit advice.

The failure of banking regulators to enact and enforce these altering and framing rules - the rules that the policy default be a true default and that banks not do anything to create the impression otherwise-with regards to overdraft reflects a lack of political will more than a flaw inherent in the use of policy defaults more broadly. ${ }^{240}$ But while such steps are a predicate for other measures that might make defaults stickier, these steps alone are unlikely to be effective. In the overdraft case, existing account holders who did not use online banking were placed in a true default position-they were not required to make any choice, and if they did nothing, they stuck with the default. Many consumers with a history of frequent overdrafts likely fell into this group, so their high opt-out rate cannot be attributed to being placed in a mandated-choice scenario.

240 I thank Professor Prentiss Cox for this point. 
What else could policymakers do? First, they might enact altering and framing rules that prevent firm maneuvers that make policy defaults slippery. Second, copying the tactics used by firms to bolster firm-set defaults, policymakers might turn to altering rules, framing rules, and affirmative governmentframing efforts that (1) create transaction barriers to opting out, (2) invoke judgment and decision biases that lead to sticking with the default, or (3) have the potential to shape consumer preferences to favor policy defaults. ${ }^{241}$ Given the ease with which banks have evaded the altering and framing rules intended to make the overdraft policy default work, these efforts would need to be significantly more extensive to be potent.

However, establishing a web of altering rules, framing rules, and affirmative government framing to support policy defaults faces a number of challenges. First, the cost of monitoring, enforcing, and adapting such regulations to respond to evolving circumstances would be high. Second, both altering and framing rules can have effects more like traditional substantive regulation. ${ }^{242}$ Although such substantive regulation is not per se problematic, it is at odds with the libertarian-paternalism premises behind the use of policy defaults rather than substantive regulation in the first instance. Third, potent framing rules have the

241 Another response might be to add substantive regulation to protect those consumers who opt out, both as a means of protecting these consumers and as an indirect way to make the default stickier by giving firms less incentive to encourage people to opt out. This is largely what consumer advocates are pressing in the context of overdraft, now that they see how slippery the default has been. See, for example, Center for Responsible Lending, Consumer Federation of America, and National Consumer Law Center, Comments at *3-4 (cited in note 78 ) (advocating limits on the number of overdraft fees that can be charged, the size of the fees, the circumstances under which the fees can be charged, and so forth). But to the extent that substantive regulation transforms the opt-out position into one that is valuable for more consumers, the policy default may then be less helpful because it imposes costs on more people who would be better off in the now-improved opt-out position. As the opt-out position becomes more valuable to consumers, it will also provide less revenue to firms, and firms will therefore spend less effort encouraging consumers to opt out. See text accompanying notes 211-19 (explaining why substantive protections for those who opt out of the over-the-limit fee default reduce credit card issuer incentives to encourage opting out). The result could be a policy default that is stickier even though fewer people ought to stick with it. Moreover, such substantive regulation is at odds with the soft paternalism billed by nudging proponents.

242 In this respect, policy defaults are no different than disclosure regulation for complex consumer products; disclosure can only make consumer markets function well when paired with substantive regulation limiting product complexity. See Lauren E. Willis, Decisionmaking and the Limits of Disclosure: The Problem of Predatory Lending: Price, 65 Md L Rev 707, 820-24 (2006) (proposing a combination of disclosure and substantive regulation so that the disclosure is useful for price shopping among home mortgages). 
potential to run afoul of protections afforded to commercial speech by current Supreme Court doctrine. Fourth, some of the tools used by firms to bolster their own defaults pose ethical concerns, concerns that are heightened when it is the government that is using these tools. Finally, to the extent that policymakers have chosen a default rather than a mandate due to a belief that some people are better off opting out of the default, they must worry about making a default too sticky.

\section{B. Altering Rules (and Complementary Framing Rules)}

1. Prohibit firms from treating consumers in the default position differently.

To make policy defaults effective, the law must prohibit firms from creating barriers to sticking with the default or giving consumers incentives to opt out. For example, banks should not be permitted to offer a day of float or credit for uncleared deposits to those who opt out of the overdraft default but not to those who do not opt out. The effect of such a rule would be that banks would stop offering these perks altogether, because banks would otherwise risk that those who had not opted out would overdraw their accounts and fail to cover the overdraft with a same-day or uncleared deposit. If a do-not-track policy default is adopted and policymakers want it to be sticky, websites must be prohibited from conditioning use on opting out or giving perks to consumers who opt out. ${ }^{243}$ Again, such an altering rule could have substantive effects. For example, to the extent that tracking enables websites to provide content, content availability could decline for all users. Although nudgers advocate defaults on the grounds that they do not limit choice, making policy defaults sticky can require substantive regulation of the products and services firms offer, with choice-limiting effects.

But requiring that firms give the same terms to consumers who do and do not opt out is not enough. Recall that nearly half of checking-account holders surveyed who had opted out of the overdraft default did so, at least in part, to be relieved of the onslaught of bank marketing. ${ }^{244}$ Firms' marketing must be

243 But see Protecting Consumer Privacy in an Era of Rapid Change at *50-52 (cited in note 207) (explaining the FTC's view that in some circumstances, it is acceptable for companies to condition use of their products or services on accepting tracking or to offer consumers who opt out lower prices or other benefits).

244 See note 148 and accompanying text. 
evenhanded, meaning firms must either ask all consumers to opt out only once ${ }^{245}$ or continue to send the same advertising regardless of whether the consumer has already opted out. Micromanaging firm marketing behavior hardly seems the easy, low-cost, soft paternalism that nudgers have touted, but it may be necessary for policy defaults opposed by firms to be effective. Moreover, as addressed further below, controlling firm marketing could run afoul of the First Amendment.

\section{Impose transaction barriers that impede opting out.}

Nudgers generally believe that opting out of policy defaults should be cheap and easy, but one tried-and-true way to make a default sticky is to impose transaction barriers on opting out.

A simple transaction barrier would be a fee or tax that a consumer must pay to opt out of the policy default. ${ }^{246}$ Even a nominal fee would create the psychological recognition that opting out is not "free"; a larger fee could counter psychological discounting of the costs of opting out. Nonfinancial opt-out transaction costs are also possible. ${ }^{247}$ A time- or hassle-intensive procedure, such as completing a long questionnaire or waiting on hold to speak with a surly service representative, could be a prerequisite for opting out. Defaults could be "reverting," meaning that consumers would be required to opt out repeatedly-for example, before each transaction that would overdraw their checking accounts. "Train-and-test" ${ }^{448}$ altering rules are another option. These could entail attending a class or counseling session about the policy default or passing a test demonstrating understanding of the default as a precondition for opting out; the costs of each of these could deter opting out. ${ }^{249}$

245 There is some precedent for this. IRS regulations permit tax preparers to ask their customers to use their tax information for marketing purposes, but the request can only be made once. 26 CFR $\S 301.7216-3(b)(3)$.

246 See Ayres, 121 Yale L J at 2088-92 (cited in note 4) (suggesting governmentimposed fees for opting out of policy defaults).

247 Id at 2076.

248 See id at 2076-80 (discussing each of these types of barriers to opting out of defaults).

249 In theory, altering rules requiring classes, counseling, or testing would decrease consumer confusion, one of the background conditions that gives power to both defaults and firm framing that encourages opting out. However, in practice these may operate more as transaction barriers than as educative tools. When Illinois required some borrowers to undergo prepurchase counseling for certain types of mortgages, transaction barriers, not increased borrower understanding of these mortgages, led to the decreased prevalence of these mortgages. See Sumit Agarwal, et al, Do Financial Counseling 
But imposing costs can be problematic, for four reasons. First, imposing costs can itself be a costly enterprise; collecting a tax, administering escrow accounts, or offering classes, counseling sessions, or tests would all require substantial resources. Second, imposing these costs on parties who opt out to their detriment harms the very consumers the policy default was established to protect. Third, there is the overdeterrence problem. It would be difficult to calibrate a cost that would deter those who ought to stick with the default and not those who ought to opt out. For example, waiting on hold might disproportionately deter consumers with little time or patience, yet these might be the very consumers who ought to opt out of the default. Fourth, firm maneuvers to minimize or neutralize opt-out costs can be expected. For example, to make opting out habitual, a bank might require account holders to check a box agreeing to opt out of the overdraft policy default "in the event that this transaction overdraws my account" every time they engage in an ATM or debit transaction. ${ }^{250}$ Requiring consumers to opt out of a do-nottrack default every time they visit a website similarly would no doubt lead firms to create opt-out buttons that consumers could click without thinking. ${ }^{251}$

Instead of imposing costs as a transaction barrier, the government might try to create confusion or harness the invisibility mechanism. ${ }^{252}$ For example, the government could strive to make the opt-out procedure confusing. But such a system would be costly, for the government to intentionally confuse its own citizens is unethical, and ultimately firms would take steps to "help" consumers overcome any confusion and successfully opt

Mandates Improve Mortgage Choice and Performance? Evidence from a Legislative Experiment *31-32 (Federal Reserve Bank of Chicago Working Paper No 2009-07, Oct 2009), online at http://www.chicagofed.org/digital_assets/publications/working_papers /2009/wp2009_07.pdf (visited Sept 11, 2013).

250 Given the current processing time for deposits and debits, banks might reasonably maintain that at the very moment the consumer uses the debit card or ATM, the bank cannot be certain whether the transaction will overdraw the account. See Government Accountability Office, Bank Fees at *54-66 (cited in note 149) (explaining barriers that prevent banks from disclosing to consumers that they are about to overdraw their accounts on a transaction-by-transaction basis).

251 See Protecting Consumer Privacy in an Era of Rapid Change at *49 (cited in note 207) (noting a "choice 'fatigue" problem when web users are repeatedly asked to opt out); Ayres, 121 Yale L J at 2069 (cited in note 4) (noting the problem that some altering rules are ineffective because people become "habituated to the speed bumps").

252 See, for example, Ayres, 121 Yale L J at 2080-83 (cited in note 4) (discussing "password" altering rules, which require parties to be sufficiently sophisticated about the transaction or the law to know the password required to opt out of policy defaults). 
out. ${ }^{253}$ Invisibility of the opt-out option could only be achieved by prohibiting firms from making consumers aware of it. ${ }^{254}$ In addition to being unethical, this would violate the First Amendment, as explained further below. A final issue is, again, overdeterrence-if the ability to opt out is truly invisible, those who ought to opt out will not.

3. Require consumers to spend time in the default position.

Requiring consumers to spend some time in the default position might increase the stickiness of defaults through loss aversion, the endowment effect, and the preference-shaping effects of experience. Experiencing the default might also educate consumers about their choices and preferences, thus mitigating the background conditions that facilitate the operation of mechanisms that can make defaults slippery. As noted above, this is already the law with regards to tax and insurance escrows for most high-cost mortgages; borrowers must escrow these with the lender for one year before opting out. ${ }^{255}$ In the case of overdraft, consumers who remain in the default position for some time might find that delaying purchases until they obtain more funds is not so onerous and is less costly than overdraft fees. While in the default position, they also might overcome any inertia or mistaken beliefs about their own overdraft usage that could have otherwise stood in the way of setting up a less expensive overdraft plan.

How long must consumers spend in the default position to better understand their choices and preferences and for loss aversion, the endowment effect, and the preference-shaping effects of experience to kick in? At a minimum, consumers would need to experience the default position at a time when it has some relevance to their lives. ${ }^{256}$ To provide experiential lessons that require behavior change, such as living without overdraft

253 Consider Gamers Opt Out, online at http://www.gamersoptout.com (visited Sept 11, 2013) (assisting video game players to opt out of firm-set defaults that waive the civil justice defaults, including class action waivers, arbitration clauses, and so forth).

254 This is a framing rule rather than an altering rule, but I discuss it here as it is a transaction barrier akin to imposing costs or confusion.

25512 CFR $\S 226.35$ (b)(iii).

256 The privacy benefits of a do-not-track default are unlikely to be appreciated through experiencing the default. Instead, users would need to experience some undesirable privacy cost and compare it to the benefits they have received from tracking. Yet by the time this cost has been incurred, information about the user has already been collected. 
coverage, could require many months in the default position..$^{257}$ For a default health insurance plan, the consumer must use the plan through various medical needs before she can understand how its coverage and cost provisions will affect her, a process that might take years. Yet requiring consumers to stay in any particular position for very long seems closer to hard paternalism than the soft paternalism that nudgers claim will be effective on its own, and harms those who are better off outside the default.

4. Delay the benefits and expedite contemplation of the costs of opting out.

Another possibility would be an altering rule that placed a delay between the decision to opt out of the policy default and gains to the consumer from opting out, and a complementary framing rule that conveyed the existence and extent of any losses caused by opting out prior to finalizing the consumer's decision to opt out. By making the consumer contemplate the costs immediately and experience the benefits later, discounting could not be used to induce consumers to opt out (and instead these biases might support the default). One industry consultant has opined that if consumers were warned of the fee they were about to be charged each time they attempted to overdraw their accounts, so few consumers would overdraw that it would "effectively kill overdraft services.” ${ }_{258}$ In a context such as internet-use tracking, where a single decision to opt out has effects over time, the consumer might be notified of the uses to which her data will be put each time she attempted to visit a new website and given the opportunity to reconsider whether she wants to visit that website.

However, delaying the benefits and expediting contemplation of the costs of opting out pose three problems. First, they could impose significant costs on consumers. Delay could harm consumers who have an immediate need for the benefits of

257 A study in Australia, where for three years after filing for bankruptcy debtors cannot obtain credit of any kind, found that debtors improved their cash management strategies significantly during this period. Further, most debtors believed the reality of lacking access to credit did not sink in and alter their behavior until six to twelve months into the experience. See Martin Ryan, The Last Resort: A Study of Consumer Bankrupts 247 (Avebury 1995).

258 Lieber and Martin, Overspending on Debit Cards, NY Times at A20 (cited in note 77) (reporting the opinion of Michael Moeb). 
opting out. For frequently repeated transactions, such as visiting a website, notifying a consumer about the privacy losses she is about to incur every time she navigates to a new website could impose significant costs; clearing her screen of a notification might take only a few seconds, but time spent reading the notices could amount to many weeks over a lifetime of internet use. ${ }^{259}$ Second, these notices are likely to be useful for only a short while, until the consumer becomes habituated and ignores them. Third, these rules could effectively amount to substantive regulation. For firms to tell consumers upfront the costs that consumers will incur would require firms to limit the costs of opting out to those costs that the firm can know with certainty at the time the consumer opts out. For example, banks could not charge a "sustained overdraft" fee because this would not be certain at the time the rule required the cost disclosure to be made. Firms that track consumer web use would be required to limit their future use of consumer data to those uses the firm disclosed at the time the consumer navigated to the website, even if future technology or market conditions create new uses for the data. These substantive constraints might be good policy, but they go well beyond setting a default.

\section{Interpose an intermediary.}

Instead of firms implementing policy defaults through direct interaction with consumers, the law might interpose an intermediary. The intermediary could ensure that the consumer intended to opt out, incidentally impose transaction costs that would deter opting out and delay that might counter time discounting, and, more ambitiously, counteract effects of firm marketing by engaging in educational efforts to ensure an informed opt-out decision.

For example, rather than having firms run the opt-out system, the government could run it in a manner inverse to the Do Not Call registry. ${ }^{260}$ In the case of a do-not-track default,

259 See Aleecia M. McDonald and Lorrie Faith Cranor, The Cost of Reading Privacy Policies, 4 I/S: J L \& Pol Info Socy 540, 560 \& table 7 (2008) (estimating based on 2008 data that, if consumers read the privacy policies of each website they visited, the average annual time spent doing so would be 244 hours, or more than half of the time consumers spend on average using the internet each year).

260 See National Do Not Call Registry, online at http://www.donotcall.gov (visited Sept 11, 2013) (allowing individuals to place their phone numbers on a list of numbers telemarketers are prohibited from calling). 
websites would be barred from tracking consumer internet use unless the consumer had signed up for the "Track Me" registry. However, while a government opt-out registry would not be expensive, enforcing its use-ferreting out which firms had tracked internet use by consumers who were not in the registry, for example-could be extremely costly. ${ }^{261}$ Further, firms will no doubt helpfully transport consumers' computer screens to the "Track Me" website or offer to opt out on consumers' behalves, eliminating the costs and procrastination that might otherwise impede opting out. ${ }^{262}$ Firm marketing could continue to play on judgment and decision biases as well. Although the government could engage in its own framing efforts on the opt-out registry website, the government is not particularly adept at marketing.

Going further, a consumer might be required to consult with an expert as a prerequisite for opting out. The costs of this, the delay it would occasion, and potential educative effects might successfully deter opting out, similar to requiring attendance at a class or counseling session discussed above. ${ }^{263}$ But the expense and overdeterrence problems of requiring a class or counseling likewise plague an expert-consultation requirement.

Intermediary systems could also have substantive effects due to their wholesale nature. Realistically, an intermediary could only be used in contexts in which the consumer makes a single opt-out decision with broad effects. For example, a Track Me registry could facilitate a consumer choice that would allow all websites to track her for all purposes, but such a registry probably could not accommodate consumers who wanted to opt out of tracking by some websites, or for some purposes, but not others. The effect would be to substantively prevent consumers from making more fine-grained opt-out decisions. ${ }^{264}$

261 Tracking technology can now avoid leaving any trace on the user's computer. See Peter Eckersley, How Unique Is Your Web Browser?, in Mikhail J. Atallah and Nicholas J. Hopper, eds, Privacy Enchancing Technologies 1, 3 (Springer 2010) (explaining a tracking system that is effective even when a user has deleted cookies and that "leaves no persistent evidence of tagging on the user's computer").

262 Note that telemarketers do not have this ability; they cannot call consumers to ask them to opt out of the Do Not Call registry, and while they could ask by mail, they cannot instantly transport consumers to a Do Not Call website to facilitate opting out.

263 See note 249 and accompanying text.

264 A web browser might seem to be an intermediary that could facilitate finegrained opt-out choices. But see note 218 (explaining that browsers cannot prevent tracking). But the more fine-grained the choices presented, the more difficult the decision process becomes, making consumers more vulnerable to confusion and firm framing encouraging consumers to opt out. 


\section{Controls on Firm Framing}

1. Prohibit firm manipulation of judgment and decision biases.

Instead of using altering rules to direct biases to bolster the default, policymakers might turn to a broad framing rule that outlaws firm maneuvers that harness these biases to work against policy defaults. However, testing all marketing for its potential to trigger judgment and decision biases would be an overwhelming task for regulators, not the easy, low-cost policy fix portrayed by nudgers.

Moreover, controls on firm marketing are likely to run afoul of First Amendment doctrine. Under that doctrine, any governmental restriction on commercial speech must (1) "directly advance" a substantial governmental interest and (2) be "narrowly tailored" to serve that interest. ${ }^{265}$ To meet the first part of this test, the government must demonstrate that such speech causes harm and that the regulation's restriction on speech will alleviate the harm "to a material degree." ${ }^{266}$ To meet the second part, the restriction must not burden substantially more speech than necessary to alleviate the harm. ${ }^{267}$ The chain of inference from any particular firm framing manipulation to a consumer's decision to opt out to that consumer being harmed is likely too long to meet the "directly advance" test. For example, firm framing of the policy default as a loss and of opting out as keeping an endowed position might lead some consumers to opt out, but this framing is unlikely to be their only reason for opting out, and therefore eliminating this marketing pitch would not necessarily lead consumers to stick with the default. Further, given that policymakers have chosen to use a policy default rather than a mandate or ban, the government must believe that some consumers are better off opting out, yet speech that might encourage them to do so could be curtailed by a rule controlling firm marketing. Because the restrictions on speech will affect both those who might benefit from it and those who might be harmed by it, these restrictions are likely too broad to meet the "narrow tailoring" test.

265 Central Hudson Gas \& Electric Corp v Public Service Commission of New York, 447 US 557, 564 (1980).

266 Edenfield v Fane, 507 US 761, 770-71 (1993).

267 See International Society for Krishna Consciousness, Inc v Lee, 505 US 672, 707 (1992) (Kennedy concurring). 
Rather than prohibiting firm speech that manipulates biases, regulators might instead attempt to require firms to engage in more speech, speech that would pivot biases back towards the policy default. Unless the regulation chills protected speech or is unduly burdensome, compelled commercial speech needs only to be "reasonably related" to the government interest advanced. ${ }^{268}$ But developing warnings, disclaimers, or other language to counter every framing manipulation used by firms would be a never-ending regulatory project. Moreover, such mandated language is likely to be relevant only at the margins, if it is helpful at all. ${ }^{269}$ For example, despite the oft-repeated line that "past performance is no guarantee of future results," consumers stubbornly chase returns in their investment decisions. ${ }^{270}$ Requiring firms to add content to their marketing that goes beyond warnings or factual information, such as the Food and Drug Administration is currently attempting to do with graphic reminders of health dangers on tobacco product packaging-while potentially much more effective than dry text-is likely to be found unconstitutional. ${ }^{271}$

As Professor David Yosifon has cogently explained, First Amendment doctrine is centrally premised on a rational actor model in which more information, however it is framed, is either helpful or, at worst, irrelevant to good decision making. ${ }^{272}$ It is

268 Zauderer $v$ Office of Disciplinary Counsel of the Supreme Court of Ohio, 471 US 626, 651 (1985).

269 See Kesten C. Green and J. Scott Armstrong, Evidence on the Effects of Mandatory Disclaimers in Advertising, 31 J Pub Pol \& Mktg 293, 297 (2012) (reviewing past experimental studies of the effects of mandatory disclaimers and finding that all such disclaimers increased consumer confusion and most were ineffective or led consumers to make worse decisions).

270 See, for example, Molly Mercer, Alan R. Palmiter, and Ahmed E. Taha, Worthless Warnings? Testing the Effectiveness of Disclaimers in Mutual Fund Advertisements, $7 \mathrm{~J}$ Empirical Legal Stud 429, 433-34 (2010).

271 Compare Discount Tobacco City \& Lottery, Inc v United States, 674 F3d 509, 518 (6th Cir 2012) (holding graphic tobacco warnings constitutional), with RJ Reynolds Tobacco Co v Food \& Drug Administration, 696 F3d 1205, 1221-22 (DC Cir 2012) (holding the same warnings unconstitutional). The Supreme Court will likely hold the graphic tobacco warnings unconstitutional. Consider Borgner v Florida Board of Dentistry, 537 US 1080, 1082 (2002) (Thomas dissenting from denial of certiorari) (suggesting that compelled commercial speech must "directly advance[]" the government's interest to survive First Amendment scrutiny, not merely bear some reasonable relationship to the government's interest); United States $v$ United Foods, Inc, 533 US 405, 416 (2001) (indicating that the "reasonably related" test for compelled commercial speech only applies when that speech is necessary to make commercial speech "nonmisleading").

272 David G. Yosifon, Resisting Deep Capture: The Commercial Speech Doctrine and Junk-Food Advertising to Children, 39 Loyola LA L Rev 507, 552-55 (2006). This is not to say that the First Amendment commercial speech doctrine could not be reconceived, 
therefore on a collision course with government regulation premised on a human judgment and decision bias model in which more information or particular framings of information can impede good decision making.

2. Simplify and clarify the decision environment.

Instead of broad prohibitions, policymakers might change the background conditions that facilitate the operation of mechanisms that can make defaults slippery by simplifying and clarifying the decision environment consumers face.

To simplify the situation, when consumers have other choices that they might confuse with the policy default, firms might be required (1) to offer a standardized, limited menu of these choices and (2) to use a standardized set of terms to describe those choices. For example, banks might be required to offer a small set of simple products that allow consumers to overdraw their accounts, and to use only distinct, standardized terms to refer to these products. But such strict framing rules would substantially limit the products that firms can offer. Again, the lesson is that to make defaults work in a complex choice environment requires hard product regulation to simplify that environment. In addition, requiring firms to use one set of terms and only one set of terms to refer to or explain a product likely runs afoul of both the "directly advance" and "narrow tailoring" requirements of the First Amendment, the former because it is not clear that such a set of standardized terms would prevent consumer confusion, and the latter because other terms could be used in a way that is not confusing.

To clarify rather than simplify, firms might be permitted to offer whatever options they choose, but also be required to present those choices in a standardized menu format that consumers could use to make both the choice whether to opt out of the default and the choice of which alternative(s) to the default to take. The PEW Charitable Trusts has made a similar suggestion in the overdraft area, proposing that banks be required to present consumers with a chart that lists overdraft product options and their key features. ${ }^{273} \mathrm{~A}$ menu might better guide consumers

see id at 560-83, but unlike Professor Yosifon, I do not believe that it is on the visible horizon of American courts' jurisprudence.

273 Weinstock, et al, Still Risky at *19 (cited in note 118). Note, however, that PEW envisions this as a separate informational document rather than as a document that could be physically check marked or electronically clicked by consumers to select among 
to the correct end positions than a policy default alone because consumers who read and understand the entire menu are more likely to make their opt-out decision based on full and accurate information. However, this presentation also might highlight the tradeoffs that must be made among the choices, thus making the decision more difficult, potentially leading to greater procrastination and, therefore, reliance on the default.

Requiring firms to present the opt-out choice as part of a menu of related choices, however, poses (1) administrative challenges for the law and (2) opportunities for firm framing manipulations. As to the former, it is difficult for the law to define which choices are sufficiently related that they all must appear in the menu. For example, should borrowing on a credit card or payday advance lending be on the same menu as overdraft choices, given that all are means of accessing short-term credit? Regarding the latter, abundant research indicates that changing the options in a menu can change consumer choices. Although adding too many options can make a default stickier due to the increased difficulty of selecting among options, other manipulations can make a default slippery. For example, adding options that appear to represent a range can increase selection of the middle option (the "compromise" effect), and adding an option that is similar but obviously inferior to another choice in the set increases the selection of the superior option (the "asymmetric dominance" or "attraction" effect). ${ }^{274}$ Firms could encourage opting out by adding or subtracting options such that the policy default is never the compromise option or the asymmetrically dominated option. For example, in the face of a "do not track, use, or share my information" policy default option A, firms could easily add options B - "track and use my information, but do not share it with any other entity" - and C_- "track, use and share my information with anyone." Option B would then be the compromise choice and the policy default (option A) could become slippery. ${ }^{275}$

overdraft coverage options. In addition, the PEW disclosure would require substantive changes in the law that would constrain the choices banks could offer to consumers (the PEW disclosure collapses overdrafts occasioned by ATM, nonrecurring debit, check, and recurring payment transactions into a single treatment) and the pricing structure used by banks for those choices (the PEW disclosure presents all costs as flat fees).

274 See, for example, Itamar Simonson, Choice Based on Reasons: The Case of Attraction and Compromise Effects, 16 J Consumer Rsrch 158, 160-62 (1989).

275 In reality, the menu of choices for internet tracking are likely to be considerably more extensive and complex, given the possible permutations (allowing tracking for some types of information but not others, for some uses but not others, by some parties but not 


\section{Affirmative Government Framing}

Instead of trying to control firm framing, the government might avoid First Amendment concerns by jumping into the frame game directly. For the government to play on people's judgment and decision biases might raise ethical concerns, but the government's use of policy defaults already implies a decision that manipulation of these biases is an acceptable means of achieving policy ends.

\section{Leverage the opt-out form.}

Provided that firms were required to use a prescribed optout form, ${ }^{276}$ much could be done to formulate that form to invoke biases that support the policy default. To harness omission bias, loss aversion, and procrastination, the form could make clear that inertia is an option, portray the default as an endowed position, and warn consumers that they will be responsible for the effects if they opt out. The form might list the benefits of sticking with the policy default prominently, both to explicitly advise consumers to stick with the default and to attempt to invoke the operation of query effects to favor the default. It could explain that the default has been selected by policymakers with consumers' interests in mind, to further convey advice.

However, the effectiveness of all of this hinges on consumers reading the form and making their opt-out decision based on the form rather than based on firm marketing. Experience with other mandated disclosures cautions that consumers rarely read them, and even when they do, they do not understand them or use the information in them accurately.277 Firm marketing is likely to reach consumers long before they see the government form, and by the time they see the form, they may have already made their decision based on that marketing. ${ }^{278}$ When sufficiently profitable to do so, firms can advise consumers in face-to-face, one-on-one meetings, and personal contact of this sort can be far

others, etc.). And the more complex the choice set, the more opportunities for framing manipulations.

276 Note that this is not the case for the overdraft opt-out form. See 12 CFR $\S 205.17$ (d) (requiring that financial institutions use forms "substantially similar" to the model form, though without providing the exact form that must be used).

277 See, for example, Omri Ben-Shahar and Carl E. Schneider, The Failure of Mandated Disclosure, 159 U Pa L Rev 647, 709-29 (2011) (explaining why consumers do not read, understand, or use disclosures).

278 See Willis, 65 Md L Rev at 791-93 (cited in note 242). 
more influential than a written form. ${ }^{279}$ As one mortgage salesman testified while explaining how he convinced people to take out unaffordable home loans despite legally required mortgage disclosures, "It is written in simple English, and it is on all the loan documents, but I can get around any figure on any loan sheet." 280

\section{Engage in government marketing.}

More directly, the government could explicitly advise consumers to stick with the policy default. Public information campaigns telling people to "Just say no" to opting out are clearly constitutional.

However, the effectiveness of public information campaigns depends on the message being persuasive, simple, clear, and achievable. ${ }^{281}$ Campaigns promoting policy defaults are unlikely to be effective for two reasons: (1) firms can muddy the message and (2) the presence of some consumers who ought to opt out requires the government to muddy the message. Firms can obscure the default position and how to stay there, preventing consumers from correctly applying the lesson of the campaign when they encounter the default. For example, a consumer taught to "just say 'no' to overdraft" might decline an overdraft-linked savings account but agree to "account protector" 282 or one of the myriad of other names that banks use for the product that opts the consumer out of the default. At the same time, the very reason regulators have chosen to use a default rather than a mandate is because they believe some consumers are better off opting out. But "Most people should just say "no" is neither persuasive nor clear. Consumers who self-select out of the "most people" group that ought to stick with the default might not be the demographic that ought to opt out. Although the message might go on to explain to consumers how to identify whether they ought to stick with the policy default or not, such instructions are not simple, nor are they likely to be clear.

\footnotetext{
279 See id at 798-804.

280 Equity Predators: Stripping, Flipping and Packing Their Way to Profits; Hearing before the Special Committee on Aging, 105th Cong, 2d Sess 30-37 (1998) (statement of "Jim Dough," former employee of a predatory lender, testifying anonymously).

281 See Jessica Aschemann-Witzel, et al, Lessons for Public Health Campaigns from Analysing Commercial Food Marketing Success Factors: A Case Study *9 (BioMed Central Public Health 2012), online at http://www.biomedcentral.com/content/pdf/1471-2458 -12-139.pdf (visited Sept 11, 2013).

282 See Standard Overdraft Service: Are You In? (cited in note 121).
} 
Even persuasive, simple, clear, and achievable public information campaigns may fail when outmaneuvered by firms. Firms are more experienced and adept at marketing than the government, and they can fine-tune their messages to different demographics and over time in ways that the government has difficulty doing. Although regulators might require firms to provide consumers with a government document advocating the policy default, firms can surround those forms with marketing that sends a very different message. If the government's message is muddled or complex, firms are handed an even better opportunity to confuse consumers. The effectiveness of a public education campaign endorsing a policy default is therefore likely to be minimal in the face of firm marketing favoring the opt-out position and firm behavior designed to minimize the influence of the government's message. ${ }^{283}$

\section{CONCLUSION}

When there is little opposition to a nudge, or the opposition that exists lacks the means to counter the nudge, nudges are likely to be successful in shaping citizens' behaviors in socially optimal ways. This is likely to be the case in transactions between citizens and the government. ${ }^{284}$ Therefore, at least where mandated choice is impracticable, the government should examine whether the current default position is the right one. Presumed consent to organ donation is a prime example. ${ }^{285}$ Some organized religious groups might oppose organ donation, but they would not be the parties that implement the opt-out process and thus would have little ability to frame the default in ways that could undermine the mechanisms that would make it stick. Some citizens may prefer not to donate, and their conscious preferences could be influenced by organized groups, but they are precisely the citizens who ought to opt out of a presumed-consent policy default. Provided that the government

283 See Theresa M. Marteau, et al, Judging Nudging: Can Nudging Improve Population Health?, 342 Brit Med J 263, 265 (2011) ("Without regulation to limit the potent effects of unhealthy nudges in existing environments shaped largely by industry, nudging towards healthier behaviour may struggle to make much impression.").

284 This is not universally true. When government actors with access to affected citizens oppose a policy default, that default will be slippery. For example, although silence is the default, arrestees, even after receiving information about their right to remain silent, almost universally opt out and talk. I thank Eric Miller for this example.

285 See generally Eric J. Johnson and Daniel Goldstein, Do Defaults Save Lives?, 302 Science 1338 (2003). 
does not place transaction barriers in the way of opting out, these citizens will do so. But for the many citizens who would either prefer to donate or whose feelings about the matter are undecided or sufficiently conflicted, a presumed-consent default would increase the number of donors and society as a whole would benefit.

Not so when firms with the power to shape the frame surrounding the nudge oppose it. Under these conditions, nudges are not the easy, low-cost, effective-without-constraining-choice policy option that nudgers have advertised. Instead, they may provide political cover for policymakers who want to appear to protect consumers, without actually helping those who need the most help.

This does not mean that opposed nudges have no benefits. For example, where consumers were not previously given or aware of the default position as an option, policy defaults can expand consumer choices and broaden consumers' consideration sets, just as mandated-choice regimes do. But the benefits are not of the magnitude envisioned by those who find inspiration in the stickiness of the retirement savings plan-participation default.

The nudgers realize that the frame in which a choice is perceived matters, but then focus on far too narrow a frame in designing policy to take advantage of this insight. ${ }^{286}$ They review the results obtained from changing a particular aspect of framing in one context and conclude that changing the same aspect in another context will lead to similar results. But in the real world, every context is different, often in consequential ways. Sometimes nudges will be effective, but for the reasons this Article explains, they often will not be.

In offering policy prescriptions, nudgers also assume a static world-one where regulation can switch the default rule, provide consumers with information, or frame information in a particular manner while everything else stays the same. But when

286 See Kyle Powys Whyte, et al, Nudge, Nudge or Shove, Shove-The Right Way for Nudges to Increase the Supply of Donated Cadaver Organs, 12 Am J Bioethics 32, 36 (Feb 2012) (explaining that nudgers need to be more sensitive to the context in which the nudge is executed, as this context will determine the success of the nudge); Tom Baker and Timothy D. Lytton, Allowing Patients to Waive the Right to Sue for Medical Malpractice: A Response to Thaler and Sunstein, 104 Nw U L Rev 233, 239-40 (2010) (arguing that making nonwaiver of the right to sue for medical malpractice the default would not prevent healthcare providers from exploiting patients' cognitive biases to convince patients to opt out). 
firms oppose nudges, they respond to the change dynamically. ${ }^{287}$ Policy defaults prevent firms from setting the default themselves, removing one arrow from firms' quivers, but not all. Providing consumers with information means firms can no longer keep consumers in the dark, but the effects of persuasive marketing can swamp the effects of information. Reframing information so that consumers are likely to make choices that increase their own or societal welfare at the expense of the firms offering those choices can only occur when consumers read the reframed information, understand it, and base their decisions upon it rather than upon firm marketing. Choice architecture is powerful if you are the one designing it. The difficulty is for the law to design it-the actual designers are often firms selling products or services to consumers, and they can run circles around the law.

This does not mean that firms are indifferent to the nudges they oppose. Firms spend money and political capital opposing policy defaults and other nudges set to serve consumer or social interests that are not aligned with their own. ${ }^{288}$ Firms incur expenses in manipulating the frame in which they present the policy defaults they oppose so as to defuse these defaults. Successful marketing to consumers with ready access to information that could discourage sales is more expensive than marketing to consumers without easy access to this information.

Firms will incur these costs only selectively. They will work to encourage consumers to opt out of policy defaults when the benefits they receive from the consumers who opt out are greater than the costs of making the default slippery for those consumers. But the situations in which firms benefit most from consumers opting out are likely to occur precisely when the cost to the consumer of opting out is high. Recall that in their campaign to move consumers to the opt-out position with respect to overdraft, banks targeted their resources at those consumers

287 See Barr, Mullainathan, and Shafir, Behaviorally Informed at *2-3 (cited in note 21) (explaining the need for regulators to take into account firm responses to behaviorally-informed policymaking - that is, nudges).

288 See, for example, Wyatt Buchanan, Social-Networking Sites Face New Privacy Battle, SFGate (San Francisco Chronicle May 14, 2011), online at http://www.sfgate.com /bayarea/article/Social-networking-sites-face-new-privacy-battle-2371641.php (visited Sept 11, 2013) (reporting on a social networking site lobbying against the internetprivacy policy default); Stacy Kaper, Overdraft Bill Held Up as Rhetoric Heats Up; Sponsors See Some Room for Compromise as Both Sides Dig In, 172 Am Banker 1 (Sept 27, 2007) (reporting on banking industry opposition to the overdraft policy default). 
who were most likely to overdraft, those who both create the most overdraft revenue for banks and would most benefit by sticking with the policy default. Ironically then, nudges could help some consumers without helping those consumers most in need of help. The cost to firms of countering nudges might even be concentrated on those same consumers, decreasing net social welfare. 289

To leave society better off, nudges faced with firm opposition must be supported by a web of regulation and government marketing so strong that the cost of cutting through that web exceeds the benefits to firms of doing so. Changing the default is not enough; regulation must also control the framing of the default and the opt-out process. But given First Amendment constraints on regulating framing by firms, policymakers are left with few options. They could try to counter firm speech with more speech, but the government generally loses marketing wars. They could enact quite substantive regulation to support the nudge. But then, why nudge? When firms oppose nudges, substantive regulation aimed directly at placing consumers in welfare-enhancing positions will certainly be more transparent, and it is likely to be more effective and less costly as well.

289 Professor David Laibson has explained how another tool advocated by nudgers, RECAP, could benefit sophisticated consumers at the expense of unsophisticated consumers. RECAP would allow consumers to take their past use history of a service and input the data into a computer tool, which then obtains complex pricing information from available service providers, analyzes the consumer's expected cost of buying the service from the providers, and tells consumers which provider is likely to be the least expensive for their use pattern. See Emir Kamenica, Sendhil Mullainathan, and Richard Thaler, Helping Consumers Know Themselves, 101 Am Econ Rev Papers \& Proc 417, 417-18 (2011). As Professor Laibson has detailed, RECAP enables firms to price discriminate in a new way. Firms can offer generally high-priced products with a few good deals hidden among their offerings. Sophisticated consumers will find those good deals using the RECAP tools. Unsophisticated consumers are unlikely to use the RECAP tools and thus unlikely to find the good deals. Sophisticated consumers might make smarter choices due to RECAP. But firms might recoup their losses from sophisticated consumer choices by raising prices on services sold to unsophisticated consumers. These ideas were expressed in David Laibson's comments on Kamenica, Mullainathan, and Thaler's paper at the American Economics Association Annual Meeting in 2011. 